\title{
Pencil Drawn Paper Based Supercapacitors
}

\author{
Michael P. Down ${ }^{1}$, Christopher W. Foster ${ }^{1}$, Xiaobo $\mathrm{Ji}^{2}$ and Craig E. Banks ${ }^{1}$
}

${ }^{1}$ : Faculty of Science and Engineering, School of Science and the Environment, Division of Chemistry and Environmental Science, Manchester Metropolitan University, Chester Street, Manchester, M1 5GD, UK

${ }^{2}$ :Key Laboratory of Resources Chemistry of Nonferrous Metals, Ministry of Education, College of Chemistry and Chemical Engineering, Central South University, Changsha, 410083 (PR China)

*To whom correspondence should be addressed.

Email: c.banks@mmu.ac.uk; Tel: ++(0)1612471196; Fax: ++(0)1612476831

Website: www.craigbanksresearch.com 


\begin{abstract}
This is the first comprehensive analysis of paper-based supercapacitors, P-SCs, that are produced utilising commercially available pencils to draw an interdigitated design upon common household printing paper, developing cheap, green and reliable low profile electrical conductors and electrodes. The P-SCs are optimised in terms of the composition of pencil used, the number of layers and the analysis of single or double sided interdigitated electrode designs; such a comprehensive study is seldom explored in previous literature.

A full analysis of the physical and electrochemical properties of the pencil drawn electrodes has been performed, including the application of a new capacitive testing/evaluation circuit applied to charge/discharge measurements/analysis which provides a revolutionary and unambiguous analysis of the capacitance of the fabricated electrodes; an easy to use experiment guide is presented. The P-SCs are benchmarked using $0.1 \mathrm{M} \mathrm{H}_{2} \mathrm{SO}_{4}$ as the aqueous electrolyte. The P-SCs demonstrate a specific capacitance of $\sim 10.6 \mu \mathrm{F} \mathrm{mg}^{-1}$ at a charge current of $0.46 \mathrm{Ag}^{-1}$. The P-SCs are integrated into a novel pouch design, providing a flexible, cheap and easily manufactured supercapacitor, which demonstrate a capacitance of $\sim 101.4 \mu \mathrm{F}$, exhibiting a specific capacitance of $\sim 42.4 \mu \mathrm{F} \mathrm{g}^{-1}$ at a current density of 0.46 $\mathrm{Ag}^{-1}$, exhibiting energy and power densities of $\sim 0.45 \mathrm{~J} \mathrm{mg}^{-1}\left(0.125 \mathrm{mWh} \mathrm{mg}^{-1}\right)$ and $\sim 0.03 \mathrm{~W} \mathrm{mg}^{-1}$ respectively. The pouch cell, fabricated from P-SCs, utilises five parallel double-sided pencil drawn electrodes, with paper separators, and retains $82.2 \%$ of its maximum capacitance, after 5121 charge/discharge cycles at a current density of $0.09 \mathrm{~A} \mathrm{~g}^{-1}$. Last, a solid state P-SC is developed utilising a PVA- $\mathrm{H}_{2} \mathrm{SO}_{4}$ solid electrolyte, which demonstrates a specific capacitance of $141.8 \mu \mathrm{F} \mathrm{g}^{-1}$, at a charging current of $4.33 \mu \mathrm{A} \mathrm{g}^{-1}$.
\end{abstract}

\title{
Introduction
}


There is currently an enormous global interest towards the design, synthesis and fabrication of improved electrodes for energy storage applications. Over recent decades the expansion of carbon based electrochemistry has received a significant focus due to these materials satisfying the aforementioned demands, with a particularly large wealth of knowledge obtained within the fields of highly ordered pyrolytic graphite, mono- and few- layer graphene, and carbon nanotubes ${ }^{1,2}$. The utilisation of 'popular' carbon based materials offers exciting advances within electrochemistry, such as the cost effective production of electrodes that exhibit a similar or enhanced performance to that of the traditional noble metal based alternatives. With electrochemists constantly searching for new electrode configurations, focus has now turned to the readily available hand-drawn pencil graphitic electrodes, where one can potentially draw their own electrode providing a rapid and extremely cost-effective approach for the production of electrochemical platforms.

Recently the possibility for using pencils to draw electrodes and other electronic components onto a suitable substrate, from paper to lithium superionic conductor films, has been reported ${ }^{3}$. Such approaches have a number of advantages; allowing the designs and geometries to be easily altered, as they are simply drawn by hand onto a suitable substrate ${ }^{4-10}$. This allows an extremely facile, green, lowcost, rapid method to fabricate electrode prototypes.

The pencil 'lead' consist of a mixture of graphite, wax and clay the proportions of which provide various properties to the resulting material. Increasing the quantity of clay creates a harder and more durable pencil, associated with the designation of ' $\mathrm{H}$ ' pencils, whereas increasing the graphite softens the resulting material but provides a blacker line associated with the designation 'B'. Established commercial mixtures vary from $6 \mathrm{~B}$, which typically contains around $84 \%$ graphite, $10 \%$ clay, and $5 \%$ wax to the common $\mathrm{HB}$, which has a general composition of $68 \%$ graphite, $26 \%$ clay, and $5 \%$ wax. The composition of different grades of commercially available pencils have been investigated by means of inductively coupled plasma mass spectrometry and time-of-flight secondary ion mass spectrometry ${ }^{11}$, 12. Pencil 'leads' or 'rods' have been established to demonstrate significantly different material properties from that of pure graphite as a result of the intercalated clay grains or particles. From varying mechanical and electrical properties, they have been shown to exhibit room temperature ferromagnetism due to the disorder of grains induced by the clay particles. Stable and intense highorder harmonics have been generated and sustained in the range $47 \mathrm{~nm}-70 \mathrm{~nm}$ in an inexpensive manner ${ }^{12}$.

A number of different electrochemical, electrical and circuit based applications for pencil drawn electrodes and conductions paths have been reported, including resistors capacitors, UV and piezoresistive/piezoelectric sensors/actuators, microfluidic devices and chemiresistive sensors, biosensors and field effect transistors have been reported ${ }^{3}$. Pencil drawing has also made an entry as an electrode material in the fabrication of these devices. Wang and Zhou ${ }^{13}$ employed pencil drawing to 
fabricate an air electrode for use in a lithium superionic conductor (LISICON) film as a solid surface for the pencil-drawing. The galvanostatic charge and discharge characteristics of the lithium-air battery were investigated showing that the capacitance value remained similar for both charging and discharging processes. This result demonstrated that $\mathrm{Li}^{+}$ions from the electrolyte and electrons from the external circuit combine reversibly with $\mathrm{O}_{2}$ from the air. Hence, the pencil-trace on the $\mathrm{Li}^{+}$ion conducting ceramic surface can serve as a catalytic electrode in a lithium-air battery, where a capacity of 500-700 mAhg-1 has been achieved ${ }^{13}$.

Solid-state supercapacitors have also been fabricated by employing pencil drawings on paper as porous electrodes ${ }^{14}$. Zheng et al. showed there is a favourable synergy among the components involved. Graphite is an excellent electrode material allowing facile formation of an electrochemical double layer. The paper substrate is an efficient dielectric separator and, being porous, allows for rapid diffusion of ionic species. Zheng et al. used a gel electrolyte was sandwiched between the two electrodes of the pencil drawings on paper ${ }^{14}$. Electrochemical testing of the supercapacitors showed high areal capacitance $\left(2.3 \mathrm{mF} \mathrm{cm}^{-2}\right)$ and an excellent long term cycling performance. They found that the specific energy and power densities of the paper supercapacitors are reasonable compared to commercial and other carbon based supercapacitors. Thus, pencil drawings on paper substrates offer a viable alternative approach for low cost and environmentally friendly energy storage devices. It should also be noted that many cases within the literature the pencils were not standard examples, but instead $99.999 \%$ purity graphite rods, from Sigma Aldrich. This presents a difficulty in the approach and application of utilising pencils and paper as a electrochemical or solid state electrical device, in that much of the literature analyses single 'pencils', under very specific conditions. Many of the reports within the literature utilise graphite rods, reallocated graphite paste and even bespoke compositions of 'pencils' to draw or fabricate the electrodes, creating a series of conditions and material properties that are difficult to replicate. Table 1 summarises the types of electrode, the electrolytes used and the method of analysis in some of the recent papers utilising the application of paper and graphite or pencils in energy storage devices. The potential for utilising paper as a substrate for 'flexible energy storage devices becomes clear in studying the applications. It is also significant that in many of these cases the 'pencil' component is either a composite material of PANI/MWCNT/etc. or not a pure or easily commercially available pencil 'lead'. Many, as proof of concepts, do not consider the effect the choice of pencil 'lead' on the application.

This paper provides a comprehensive characterisation of the Paper based SuperCapacitors, P-SCs, and the conductive properties of the pencil drawn electrodes, characterising the electrical resistivity of various composition of pencil, the morphological and electrochemical charge/discharge properties of these paper based supercapacitors featuring pencil drawn electrodes. All with the aim of providing an analytical and comprehensive approach for the development and characterisation of paper based 
supercapacitors. A simple capacitive circuit, proposed by Kampouris et al., has been shown to provide comprehensive analysis of the capacitive charge and discharge properties of supercapacitors, providing unambiguous results ${ }^{15}$. This study will utilise this capacitive circuit in the characterisation of the supercapacitors and provide explicit evidence for the benefit of utilising such an approach in the design and characterisation of materials for electrodes and supercapacitor applications. The optimisation of double-sided pencil drawn electrodes provides the basis for the development of a flexible paper-based pouch supercapacitor. In addition a solid state paper based supercapacitor is develop utilising a PVA$\mathrm{H}_{2} \mathrm{SO}_{4}$ solid electrolyte. 


\section{Experimental section}

All chemicals used were of an analytical grade and used without any further purification from SigmaAldrich. The solutions were prepared with deionised water of resistivity not less than $18 \mathrm{M} \Omega \mathrm{cm}$. All electrochemical measurements were performed with a $\mu$ Autolab TYPE III (Autolab, The Netherlands). Commonly available printing paper $\left(75 \mathrm{~g} \mathrm{~m}^{-2}\right.$, Lenzing Paper, UK) was utilised as the drawing surface for all electrodes. Commercially available Derwent ${ }^{\mathrm{TM}}$ pencils, ranging from $\mathrm{HB}$ to $9 \mathrm{~B}$ were employed, providing a range of samples/electrodes with various graphitic content and properties. A series of stencils were drawn using Solidworks, and CNC milled out of a sheet of $1 \mathrm{~mm}$ thick stainless steel, (SS316), to provide a series of stencils of known dimensions, shown in Figure $1 \mathrm{~A}$. The stencils provide a number of designs, of fixed width $(2 \mathrm{~cm})$ and varying lengths, which provides group of pencil drawn resistors of varying length, and hence resistance, which allow characterisation of the electrical conductivity of pencil drawn conduction paths and electrodes. The benefit of drawing a number of conduction paths rather than one is that this provides a representative study of the reproducibility of pencil drawn electronics and electrodes. An interdigitated electrode design is also milled from stainless steel, the dimensions of which are shown in Figure 1B and 1C, which provides a repeatable electrode design for uniform electrochemical testing conditions. In order to provide a uniform sample range each electrode was developed with a controlled number of traces. In this case, a single trace was defined as the area a pencil is in contact with the paper and has run over the surface and returned along the same path, providing a uniform layer of graphitic material whilst minimising any risk of anisotropy.

The morphology and structure of the pencil drawn resistors and electrodes were analysed via means Scanning Electron Microscopy (SEM) (JEOL JSM-840), and EDX. In the case of electrochemical analysis, the interdigitated electrode design utilises one side as the working electrode and the opposite as the counter and reference both. The weight of the graphitic material deposited was measures by a microbalance AE ADAM PW124 microbalance with an accuracy of $0.1 \mathrm{mg}$. Electrical resistance measurements were carried out utilising a 4-wire measurement method, usually used to measure small resistances in thin films. The benefit of this system prevents the resistance in the wires and connectors from being included in any measurements. The sheet resistance is determined utilising the Van der Pauw method ${ }^{16}$.

A solid state P-SC is developed utilising two independent pencil drawn electrodes of dimensions $2 \mathrm{~cm}$ width and $10 \mathrm{~cm}$ in length. A 'solid' or gel electrolyte is developed utilising a $50 \mathrm{~mL} 1.0 \mathrm{M} \mathrm{H}_{2} \mathrm{SO}_{4}$ aqueous solution mixed with $5 \mathrm{~g}$ of polyvinyl alcohol. The solution is mixed at approximately $80{ }^{\circ} \mathrm{C}$, thoroughly until a gel is formed. The electrodes are immersed in the gel at the same temperature to allow a thorough and uniform coating. The resulting electrodes are left to dry for 12 hours, before being forced together to form a three layer system consisting of paper drawn electrodes sandwiching either side of a solid electrolyte. 


\section{Results and Discussion}

The pencil electrodes and conductions paths were drawn onto the paper substrate, utilising the stainless steel cut-outs, for a 20 traces, in this case defined as the tracking of a pencil of the surface in one direction and returning along the same path to provide one trace. The characterisation of the morphological properties of the pencil traces on paper surfaces is carried out by means of SEM. This determines potential applications and properties as well as potential failure mechanisms. The SEM images of the pencil drawn electrodes are shown in Figures 2A-D which show that the paper substrate consists of cellulose fibres, approximately $20 \mu \mathrm{m}$ in diameter, which are randomly oriented and flattened, generating the surface of the paper with good exfoliation properties. The $45^{\circ}$ cross sectional images, in Figures 2A and 2B show that the porosity of the cellulose network that forms the paper substrate remains consistent both away from and underneath the graphitic track, indicating the process of drawing the conduction paths and electrodes has negligible effect on the structural properties of the paper. The benefit of this is that the paper will likely allow fluid to penetrate into the substrate and interact with the pencil trace from all sides. The graphitic track deposits relatively uniformly onto the surface, with well-deformed edges. There also appears to be a number of grains/flakes on the surface demonstrating a number of features that appear to be edge planes. The grains vary in size from $10 \mu \mathrm{m}$ to $200 \mu \mathrm{m}$ and are oriented randomly upon the track. The structural morphology of the pencil tracks appears to be independent of the pencil composition used, because of the random nature of the mechanical exfoliation deposition mechanism.

The EDX of several of the compositions, (HB, 3B, 6B and 9B) are depicted in Figure 2E, the results displayed are normalised in terms of the intensity of the carbon peak present in each spectrum, providing a relative analysis of the content of alternative materials present in the conduction paths. The EDX is carried out across the pencil drawn resistor more than $100 \mu \mathrm{m}$ from the edge of the conduction path. The HB pencil demonstrates a larger proportion of the peaks outside of the carbon peak, relative to the $3 \mathrm{~B}, 6 \mathrm{~B}$ and 9B, illustrating the higher clay and wax content in the pencil track. As recorded in the literature, increasing the "B" number increases the graphite content, as supported here, where 9B demonstrates the highest carbon content of the pencils investigated.

Having demonstrated that the pencil compositions, although of the same constituent parts, are in varying concentrations of graphite, the effect this has upon the electrical resistivity of the drawn components is investigated. In order to determine the performance of the pencil drawn electrodes, the resistivity of various track dimensions are considered. A pencil trace on paper is essentially a graphitic resistor, in which the resistance varies, as expected, with its physical dimensions - length, width and thickness, and these changes are indicative of the electrical resistivity of the traces. The stencils are drawn out with each pencil at five traces, providing a number of lengths for each pencil. The electrical resistance across each of the pencil conduction paths was measured utilising the 4-wire measurement system. 
Figure 3A shows the electrical resistance as a function of length for each of the pencils. The decrease in the electrical resistance with the " $\mathrm{B}$ " grade can be associated to the increase in graphitic concentration shown by the EDX of the pencil tracks. This demonstrates the negative effect that the wax and clay components of the pencil 'lead' have upon the electrical conductivity as the graphite is the electrically conducting component. The electrical resistances occupy common required ranges, from $100 \Omega$ to 1 $\mathrm{k} \Omega$, demonstrating reliable conductive paths, this is highlighted by using the resistor to control the brightness of an LED, shown in Figure 3B. The measured resistances vary from $39 \Omega$ for the $9 \mathrm{~B}$ at 1 $\mathrm{cm}$ up to $898 \Omega$ for the HB at $11 \mathrm{~cm}$. The expected linear trend is observed in resistance with respect to length, the gradient of which is proportional to the resistivity of the material, resulting in the HB demonstrating the highest resistances, as a result of the low graphite concentration. Despite this, all of the pencils utilised demonstrate acceptable sheet resistance values from $109 \Omega \mathrm{sq}^{-1}$ to $556 \Omega \mathrm{sq}^{-1}$ for $9 \mathrm{~B}$ and $\mathrm{HB}$ respectively as shown in Figure 3B. The values here represent the sheet resistance determined by the Van de Pauw method, presenting an average and standard deviation of the sheet resistance in a number of orientations.

Cyclic voltammetry of the pencil drawn interdigitated pencil drawn electrodes was carried over the range of $-1.0 \mathrm{~V}$ to $1.0 \mathrm{~V}$, with a fixed scan rate of $25 \mathrm{mVs}^{-1}$. It is well known that a high concentration of $\mathrm{H}_{2} \mathrm{SO}_{4}$ can corrode paper, which is the support of the supercapacitor, however a dilute solution of $0.1 \mathrm{M}$ was used throughout to overcome this issue. The porosity of the paper substrate is likely to promote the penetration of the solution into the structure and as such the time submerged is considered a contributing variable to the analyses of the electrochemical properties of the electrodes. To investigate this the effect of the time submerged within the electrolyte on the cyclic voltammetry is also investigated. The analysis of the electrodes is carried out for both single sided, where the interdigitated design is drawn onto one side, and double sided, where the design is on both sides. It was shown that having double-sided, or 'back-to-back' electrodes can improve the reliability, and signal strength as a result of the increased surface area ${ }^{17}$. This effect is even more important in terms of paper-based electrodes, where the electrolyte can penetrate into the paper, it is expected that it can then interact with the graphite electrode on the paper surface from both the exterior surface and the interior of the paper. Cyclic voltammetry is performed after various times from the moment that the electrodes are submerged. The change in the voltammogram will provide information on the nature of the electrodes, and whether the electrolyte can penetrate into the cellulose network of the paper substrate, and if so how long the system takes to settle to equilibrium.

Typical cyclic voltammograms are shown in Figures 4A and 4B, where the effect of the penetration of the electrolyte into the paper substrate can be observed, in both cases the area of the voltammograms increases with respect to time, indicating an improvement in the electrode area and capacitance. The improvement is slight however considering the non-uniformity of the single sided electrode after 0 minutes soaking, the soaking of the sample in the electrolyte is a clearly beneficial step to take in the 
analysis and development of a paper based super-capacitor. The results here suggest that the effect on the double-sided electrode are slight and relatively stable over 30 minutes in the solution, as a result all further electrodes considered are analysed using double sided electrodes after 30 minutes of soaking in the electrolyte.

Given the relatively random deposition of graphitic material on the surface using the mechanical exfoliation involved in drawing, the effect of changing the quantity of material on the paper surface is also investigated. The material is deposited onto the paper by running the pencil across the surface first in one direction and then in reverse along the same path, defining one trace. This, ideally, would deposit two uniform layer of graphitic material on the paper surfaces, however realistically the deposition by mechanical exfoliation is relatively random. As such, the effect of changing the number of traces, as defined earlier is investigated. Figure $5 \mathrm{~A}$ shows the voltammograms for the $8 \mathrm{~B}$ pencil over a different number of traces. The increase in the number of traces of the pencil has a clear effect on the shape of the voltammogram, increasing in volume as the number of traces increases, indicating the increase in graphite content on the surfaces.

Another variable in the process of manufacturing pencil drawn electrodes is the composition of the pencil. It has already been shown that the different compositions have different concentrations of graphite in the material, and, consequently varying electrical conductivity and sheet resistance values. The impact of this on the behaviour as electrochemical electrodes is yet to be investigated. As a result, in order to determine the best pencil composition for application as supercapacitor electrodes the cyclic voltammetry for each is also compared. Figure 4 shows the voltammogram of pencils $\mathrm{HB}$ to $9 \mathrm{~B}$. There is a general trend in the voltammograms for the pencils, increasing in bulbosity as the "B" number, and consequently the graphite content, increases. The one exception to this being the case of the $8 \mathrm{~B}$ and $9 \mathrm{~B}$ electrodes. The $8 \mathrm{~B}$ demonstrates a significantly higher area when compared to the 9B. This demonstrates a surprising result as the $9 \mathrm{~B}$ has been shown to have a higher graphite content and lower electrical resistances as shown in Table 2. It is proposed that this is the result of the graphite content having poor adhesion to the paper surface, and at high concentrations, the pencil graphite tracks can easily be removed from the surface during submersion into the aqueous electrolyte. This demonstrates the purpose of the clay and wax present in the pencils, which act as a binding agent, holding the graphite material on the paper surface whilst the electrode is immersed in the electrolyte solution.

The charge-discharge characteristics of any supercapacitors are vitally important, indicating the capacitance and efficiency of the devices. The pencil traces are tested as supercapacitors as electrodes by means of galvanostatic DC analysis, providing charge/discharge characteristics of the drawn electrodes, in a $0.1 \mathrm{M} \mathrm{H}_{2} \mathrm{SO}_{4}$ aqueous solution. Typically, the capacitance, $C_{\text {total }}$, of the supercapacitor is evaluated from the slope of the charge/discharge cycles using the equation below. 


$$
C_{\text {total }}=\frac{I}{(d V / d t)}
$$

where $I$ is the current applied, $V$ is the potential measured over time, $t$.

In order to perform capacitive analysis of the electrodes a novel capacitive circuit proposed by Kampouris et al. was integrated into the analysis ${ }^{15}$. The circuit proposed is shown in Figure 1D, where the circuit is in situ in the potentiostat arrangement and Figure 1E depicts how the sample and circuit are arranged; an additional capacitor, of known capacitance, is added in parallel to the electrode. The benefit of this parallel capacitor is that the resulting charge/discharge curve is significantly easier to interpret. The system demonstrates a linear, or near linear, change in potential over time. As a result of a supporting capacitor ensuring the charge of the system does not begin to saturate, which cause the plateau of the potential frequently observed in such analyses. The charge-discharge behaviour of the total system is then related to the total capacitance of the parallel circuit. The total capacitance being then sum of the capacitance of the systems components:

$$
C_{\text {total }}=C_{1}+C_{2}+C_{3} \ldots=\sum_{i} C_{i}
$$

The capacitance of the circuit can therefore be determined as the sum of the capacitance of the working electrode, $C_{W E}$, the counter electrode, which is assumed to be equal to $C_{W E}$, and the capacitance of the parallel circuit, $C_{K n o w n}$; such that:

$$
C_{\text {total }}=C_{\text {Known }}+2 C_{W E}
$$

and therefore:

$$
C_{W E}=\frac{1}{2}\left(C_{\text {total }}-C_{\text {known }}\right)
$$

and from equation 1 :

$$
C_{W E}=\frac{1}{2}\left(\frac{I}{d V / d t}-C_{\text {known }}\right)
$$

where $C_{W E}$ is the capacitance exhibited by the working electrode, $d V / d t$ is the slope of the potential of the total device with regards to time. The specific energy of the capacitor is then:

$$
E=I \frac{(d V)(d t)}{2 m}
$$


and the specific power is:

$$
P=I \frac{(d V)}{2 m}
$$

On many occasions, the slop of $V$ against $t$ does not have a distinct uniform value, rather a range of decreasing values as the gradient plateaus at the charge saturation point of the capacitor. The interpretation of the real capacitance of the electrode is therefore difficult, providing results that are incomparable to other studies. The addition of the capacitor is for this exact purpose; to produce a linear response from the potential, thus allowing an exact and constant value for $d V / d t$ to be determined, and provide a comparable and repeatable analysis. The approach here is a standardised approach for the development and characterisation of supercapacitors, reducing complications with the interpretation of the experimental data.

In the case of pencil drawn electrodes, as shown in Figure 6A, the charge-discharge curves are highly non uniform, resulting in a complication in the interpretation of the behaviour and capabilities of the capacitor. Figure 6B demonstrates a comprehensive analysis of the change in gradient during the period of one charge from cycles number 100 to 120 , demonstrating a number of regions the gradient can be selected from generating values from 0.005 to 0.035 for the average trend of cycles 100 to 120 . This equates to a capacitance range of $20.2 \mu \mathrm{F}$ to $142 \mu \mathrm{F}$ for the $8 \mathrm{~B}$ pencil drawn electrodes with a \pm 50.0 $\mu \mathrm{A}$ charging/discharging current. This is the benefit of utilising the circuit integrated into the analysis circuit, as shown in Figure 1E. Where instead of analysing a complicated curve, we can solve for a single straight line, related to the combined capacitance of the parallel capacitor and the electrode in question. Figure 6A shows the charge/discharge of the circuit and electrodes for parallel capacitance from 0 to $620 \mu \mathrm{F}$. In this case, we can see that the inclusion of the circuit provides a straight-line charge/discharge response where the gradient is related to the total capacitance of the system. The values of the capacitance for each of the values of the variable capacitor are summarised in table 3 . Here we can see that with the circuit in place the range of capacitances reduces to $19.6 \mu \mathrm{F}$ to $40.0 \mu \mathrm{F}$. The results utilising the capacitive circuit significantly reduce the range of the capacitive values in the analysis as a result of the integrated circuit providing a more uniform gradient. The effect of changing the current densities, the equivalent of increasing the current from 5 to $30 \mu \mathrm{A}$, is shown in Figure 7 . Here it can be seen that the pencil drawn electrode is capable of sustaining relatively high charging currents without demonstrating a significant reduction in the performance. The $8 \mathrm{~B}$ pencil drawn electrode is demonstrating significant capabilities as an electrochemical electrode, demonstrating relatively reliable capacitance considering the ease and cost of the electrode manufacturing. The pencil drawn electrode also seems to demonstrate good longevity with the charge-discharge behaviour demonstrating little-to-no change after 100 cycles. 
In order to evaluate whether the principal of pencil drawn electrodess can be utilised in a practical application, or generate higher, more useful capacitances a simple test structure of a P-SC consisting pencil drawn electrodes is developed. A small pouch is filled with a 5 pencil drawn electrodes, double sided as previously, separated by means of blank paper spacers, the electrodes are connected by short distances of copper wire and connected to the potentiostat by crocodile clips. The pouch is filled with $3 \mathrm{~mL}$ of $0.1 \mathrm{M}$ of $\mathrm{H}_{2} \mathrm{SO}_{4}$ electrolyte, as used previously to complete the supercapacitor. Figure 8 shows a photograph of the prototype device in situ during charge/discharge analysis. The pouch capacitor is charged and discharged of a current of $\pm 5.0 \mu \mathrm{A}$ as previously, as shown in Figure 8. The charge/discharge of the pouch without the circuit demonstrates the same characteristic plateau as the charge and discharge cycle continues, causing the same difficulty in interpreting the capacitance of the electrode. To solve this the capacitive circuit is applied again utilising a $620 \mu \mathrm{F}$ capacitor. The resulting charge/discharge curve is significantly more linear and provides a significantly more linear response as shown in Figure 7A.

The application of the P-SC have demonstrated a significant performance at low cost. In order to assess the potential applications of such devices the longevity and consistency of the device is tested. The device remained in testing for 10 days and was cycled intermittently at $0.03 \mathrm{~Hz}$ over 5000 cycles. Figure 9A shows the charge/discharge characteristics of cycle numbers 1 to 5001 in intervals of 1000, demonstrating the uniformity of the device over a large number of cycles and a large time. Figure 9B shows the evolution of the capacitance over this period. Showing a strong and relatively consistent performance over the 5000 cycles. The performance improves by nearly $400 \%$ over the first 200 cycles, likely a consequence of the electrolyte penetrating into the layers of paper, which is likely to take longer than the 30 minutes in the previous tests with the increase in the volume of paper. After this initial stage the supercapacitor demonstrates a relatively stable performance of around $200 \mu \mathrm{F}$ with fluctuations of about $10 \%$, likely related to temperature fluctuations and laboratory conditions over such a long analysis. Towards the end of the test a slight decrease in the performance is noticed however, the device remains well within $10 \%$ of the maximum capacitance of the device.

The P-SC demonstrates a highly consistent level of performance over the testing lifetime of the device, and demonstrates no significant failures after 10 days of testing. One of the major benefits of utilising such material is the flexibility of the final device. Such a device or design is highly popular in the field of wearable technologies and flexible electronics. The P-SC is tested having been folded and held at an angle, shown in Figure 10. It can be seen that the application of a force to the pouch, bending the system has a negative effect on the performance of the pouch, reducing the efficiency of device by $20 \%$, from $182.2 \mu \mathrm{F}$, at the beginning of this test, to $147.3 \mu \mathrm{F}$. This is likely a result of the weakening of the paper substrate after such a long test period. However, despite this performance drop, the P-SC remain functional. Indicating that perhaps with a more resilient substrate the device may remain $100 \%$ effective after this test period. 
An alternative to such a device, which integrates a solution and electrodes into a flexible pouch arrangement, is a solid-state system or near-solid-state system where each of the component is a flexible. This requires the flexible paper based electrodes to be combined with a flexible electrolyte. An example of this is manufactured utilising a PVA-based-electrolyte component, where $50 \mathrm{~mL} 1.0 \mathrm{M} \mathrm{H}_{2} \mathrm{SO}_{4}$ is mixed at roughly $80{ }^{\circ} \mathrm{C}$ with $5 \mathrm{~g}$ PVA pellets until a gel/viscous fluid is formed. Paper strips, with a conduction path drawn upon them of $2 \mathrm{~cm}$ width and $10 \mathrm{~cm}$ length, are submerged in the electrolyte whilst it is still heated. They are removed and left to dry for several hours, before being pressed together uniformly across the surface, with $1 \mathrm{~cm}$ overlap on either side for a connection, given a $9 \mathrm{~cm} \times 2 \mathrm{~cm}$ overlap of the solid-state capacitor's electrodes. This system is left to dry and settle for several more hours before being tested with the same charging current and conditions as the pouch arrangement. Figure 11A shows the resulting solid-state P-SC in situ during charge/discharge characterisation testing, the results of which are shown in Figure 11B. The solid-state P-SC is shown to have a capacitance of 164.1 $\mu \mathrm{F}$, which is equivalent to $141.8 \mu \mathrm{F} \mathrm{g}^{-1}$, with a charging current of $4.33 \mu \mathrm{A} \mathrm{g}^{-1}(5.0 \mu \mathrm{A})$. The resulting devices demonstrate both comparable performance for flexible, green and facile supercapacitor devices, and low-cost solutions for experimental and novel applications. 


\section{Conclusions}

Pencil traces, drawn with commercially available pencils on commercially available paper, have demonstrated significant capabilities and remarkable properties. The composition of pencils have been shown to provide a range of sheet resistance values, from 109 to $556 \Omega \mathrm{sq}^{-1}$, demonstrating the potential of the traces to provide a basis for low profile hand drawn electronic devices, prototype test structures and electrodes for flexible, paper based energy storage device. The optimal pencil composition is identified by considering the voltammograms, where the area is related to the capacitance. The 8B is identified as the most suitable pencil for electrochemical applications, despite the $9 \mathrm{~B}$ having the highest carbon concentration of all the pencils tested. This is likely a consequence of the reduced quantity of wax and clay in the pencil 'leads', which act as binding or adhesive components, holding the deposited material on the surface. The effect of providing more electrically conducting material is considered by varying the number of traces is also considered. It was shown that increasing the number of traces directly affects the area of the voltammogram, demonstrating that increasing the number of traces provides more material on the surface, improving the capacitance of the electrode.

The process of developing and characterising such pencil drawn electrode has also been considered. Where typically the testing of the capacitance of similar electrodes can provide difficult data to interpret, this paper has demonstrated the application of a parallel circuit, which has been shown to provide significantly more uniform charge/discharge properties, significantly reducing the range of capacitances that could be considered as the true value. This work/supercapacitor demonstrates capacitance values from 6.123 to $12.307 \mu \mathrm{F} \mathrm{mg}^{-1}$, the pencil drawn electrodes demonstrate a good basis for the application of test electrodes for testing hypothesis, electrode designs or electrolyte behaviour. The difficulties of using pencil drawn electrodes are providing uniformity in the fabricated electrode; the scale of the errors in the resistance and sheet resistance measurement indicate the variability in each sample. 
Table 1. A summary of the previous literature featuring 'pencil' drawn electrodes, paper based supercapacitors, or combinations of both, where $C_{W E}$, is the capacitance of the working electrodes, $C_{s}$ is the specific capacity, $C_{a}$ is the areal capacitance, $I$ is the applied current and $N_{E}$ is the number of electrodes used in the analysis. It becomes clear that there is not a standardised way to interpret the capacitance of an electrode.

\begin{tabular}{|c|c|c|c|c|}
\hline Electrode & Electrolyte & Method & Performance & Ref \\
\hline $\begin{array}{l}\text { Graphite - Sigma Aldrich, } \\
\text { 99.999\% purity. } \\
\text { Paper - Commercial Xerox. }\end{array}$ & $\begin{array}{l}1 \mathrm{M} \mathrm{H}_{2} \mathrm{SO}_{4} \text { soaked } \\
\text { and then sealed in } \\
\text { polymer bag. }\end{array}$ & $\begin{array}{l}\text { Electrodes submerged in electrolyte for } \\
10 \mathrm{mins}, \text { removed and sealed in bag. }\end{array}$ & $\begin{array}{c}I_{S}=500 \mathrm{mAg}^{-1} \\
C_{W E}=1.13 \mathrm{mF} \\
C_{s}=23 \mathrm{~F} \mathrm{~g}^{-1} \\
C_{a}=1.13 \mathrm{mF} \mathrm{cm} \mathrm{cm}^{-2} \\
N_{E}=3\end{array}$ & 14 \\
\hline $\begin{array}{l}\text { G/PANI-Paper (Pencil } \\
\text { Graphite used as a growth } \\
\text { catalyst for Poly Aniline } \\
\text { nanofiber network on cellulose } \\
\text { paper). }\end{array}$ & $\begin{array}{l}\mathrm{PVA} / \mathrm{H}_{3} \mathrm{PO}_{4} \text { and } \\
\mathrm{PVA} / \mathrm{KOH} \\
\text { electrolyte gels. }\end{array}$ & $\begin{array}{l}\text { Electrodes submerged in electrolyte and sealed } \\
\text { in bag with additional electrolyte. }\end{array}$ & $\begin{array}{c}I=1-10 \mathrm{Ag}^{-1} \\
C_{W E}=\text { Not reported } \\
C_{S}=490-763 \mathrm{~F} \mathrm{~g}^{-1} \\
C_{a}=\text { Not reported } \\
N_{E}=2\end{array}$ & 18 \\
\hline $\begin{array}{l}\text { Novel Cellulose NanoFibre } \\
\text { (CNF) - Graphene Oxide } \\
\text { Nanosheets hybrid aerogel as } \\
\text { the electrode material. }\end{array}$ & $\begin{array}{l}\mathrm{PVA} / \mathrm{H}_{3} \mathrm{PO}_{4} \\
\text { Electrolyte gel. }\end{array}$ & $\begin{array}{l}\text { The CNF-RGO (20\%) hybrid aerogel is used } \\
\text { to fabricate all solid-state flexible } \\
\text { supercapacitors without need for any other } \\
\text { binders and electroactive additives. The } \\
\mathrm{H}_{2} \mathrm{SO}_{4}-\text { polyvinyl (PVA) gel is chosen as the } \\
\text { electrolyte and it also performs the function of } \\
\text { a separator. }\end{array}$ & $\begin{array}{c}I=0.7-5.6 \mathrm{~mA} \mathrm{~cm}^{-2} \\
C_{W E}=158 \mathrm{mF} \mathrm{cm}^{-2} \\
C_{s}=207 \mathrm{~F} \mathrm{~g}^{-1} \\
C_{a}=\text { Not reported } \\
N_{E}=3\end{array}$ & 19 \\
\hline $\begin{array}{l}\text { MWCNT "assisted" PANI or } \\
\text { MWCNT-PANI. }\end{array}$ & $\begin{array}{l}\mathrm{PVA} / \mathrm{H}_{3} \mathrm{PO}_{4} \\
\text { Electrolyte gel. }\end{array}$ & $\begin{array}{l}\text { Tested as asymmetric solid state } \\
\text { supercapacitor (ASS) and symmetric solid- } \\
\text { state supercapacitor (SSS) devices. }\end{array}$ & $\begin{array}{c}I=0.5 \mathrm{~mA} \\
C_{W E}=34.6 \mathrm{mF} \\
C_{s}=510 \mathrm{~F} \mathrm{~g} \mathrm{~g}^{-1} \\
C_{a}=23.1 \mathrm{mF} \mathrm{cm}^{-2} \\
N_{E}=3\end{array}$ & 20 \\
\hline $\begin{array}{l}\text { Vanadium Oxide coating on } \\
\text { MWCNT. }\end{array}$ & $\mathrm{KCl}$ and $\mathrm{LiClO}_{4}$ & $\begin{array}{l}8 \mathrm{M} \mathrm{LiCl} \text { due to very high solubility in } \\
\text { aqueous solutions. }\end{array}$ & $\begin{array}{c}I=1-20 \mathrm{Ag}^{-1} \\
C_{W E}=\text { Not reported } \\
C_{S}=1550 \mathrm{Fg}^{-1}\end{array}$ & 21 \\
\hline
\end{tabular}




\begin{tabular}{|c|c|c|c|c|}
\hline & & & $\begin{array}{c}C_{a}=\text { Not reported } \\
N_{E}=2\end{array}$ & \\
\hline $\begin{array}{l}3 \mathrm{D} \text { porous spinous iron oxide } \\
\text { materials synthesized on a thin } \\
\text { iron plate. }\end{array}$ & $\begin{array}{l}\mathrm{Na}_{2} \mathrm{SO}_{4} \text { and } \\
\mathrm{LiPF}_{6} / \mathrm{EC}: \mathrm{DEC} .\end{array}$ & $\begin{array}{l}\text { Cyclic voltammetry, and galvanostatic charge- } \\
\text { discharge. }\end{array}$ & $\begin{array}{c}I=1 \mathrm{~A} \mathrm{~g}^{-1} \\
C_{W E}=\text { Not reported } \\
C_{S}=5246 \mathrm{~F} \mathrm{~g}^{-1} \\
C_{a}=\text { Not reported } \\
N_{E}=2\end{array}$ & 22 \\
\hline $\begin{array}{l}\text { 3D hierarchical hybrid } \\
\text { mesoporous } \\
\mathrm{NiCo}_{2} \mathrm{O}_{4} @ \mathrm{Co}_{x} \mathrm{Ni}_{1-\mathrm{x}}(\mathrm{OH})_{2} \\
\text { core-shell nanosheet arrays on } \\
\mathrm{Ni} \text { foam rationally designed } \\
\text { and synthesized via an } \\
\text { electrodeposited routine. }\end{array}$ & $1 \mathrm{M} \mathrm{KOH}$. & $\begin{array}{l}\text { Cyclic voltammetry, and galvanostatic charge- } \\
\text { discharge. }\end{array}$ & $\begin{array}{c}I=1 \mathrm{~mA} \\
C_{W E}=\text { Not reported } \\
C_{s}=121 \mathrm{Fg}^{-1} \\
C_{a}=\text { Not reported } \\
N_{E}=3\end{array}$ & 23 \\
\hline $\begin{array}{l}\text { Hybrid ternary } \\
\text { nanocomposites, comprised of } \\
\text { rice paper, single-walled } \\
\text { carbon nanotubes (SWCNTs) } \\
\text { and manganese oxide } \\
\text { nanoparticles. }\end{array}$ & $0.5 \mathrm{M} \mathrm{Na}_{2} \mathrm{SO}_{4}$ & $\begin{array}{l}\text { Each supercapacitor consists of two electrodes } \\
\text { of the same type of materials, two platinum } \\
\text { foils (Sigma, } 99.99 \% \text { ) as current collectors, a } \\
\text { piece of membrane (Nippon Kodoshi Co.) as } \\
\text { the separator. Cyclic voltammetry (CV), } \\
\text { galvanostatic charge and discharge, } \\
\text { electrochemical impedance spectroscopy } \\
\text { (EIS), and capacitance retention tests. }\end{array}$ & $\begin{array}{c}I=0.5-5 \mathrm{Ag}^{-1} \\
C_{W E}=\text { Not reported } \\
C_{S}=60.4-260.2 \mathrm{Fg}^{-1} \\
C_{a}=\text { Not reported } \\
N_{E}=2\end{array}$ & 24 \\
\hline $\begin{array}{l}3 \mathrm{D} \text { hollow } \mathrm{MnO}_{2} / \mathrm{C} \\
\text { composites. (Employing } \\
\text { renewable cost effective and } \\
\text { widespread naturally porous } \\
\text { lotus pollen). }\end{array}$ & $1 \mathrm{M} \mathrm{H}_{2} \mathrm{SO}_{4}$. & $\begin{array}{l}\text { Cyclic voltammetry }(\mathrm{CV}) \text {, galvanostatic charge } \\
\text { and discharge. }\end{array}$ & $\begin{array}{c}I=0.5 \mathrm{~A} \mathrm{~g}^{-1} \\
C_{W E}=\text { Not reported } \\
C_{s}=257 \mathrm{~F} \mathrm{~g}^{-1} \\
C_{a}=\text { Not reported } \\
N_{E}=2\end{array}$ & 25 \\
\hline $\begin{array}{l}\text { Porous hybrid graphene-- } \\
\text { carbon nanotube (G-CNT) } \\
\text { layer on the carbon fiber } \\
\text { surface of carbon cloth }(\mathrm{CC}) \text {. }\end{array}$ & $1.0 \mathrm{M} \mathrm{H}_{2} \mathrm{SO}_{4}$. & $\begin{array}{l}\text { Cyclic voltammetry }(\mathrm{CV}) \text {, galvanostatic charge } \\
\text { and discharge. }\end{array}$ & $\begin{array}{c}I=1-2 \mathrm{Ag}^{-1} \\
C_{W E}=\text { Not reported } \\
C_{S}=62.0-142.0 \mathrm{Fg}^{-1} \\
C_{a}=\text { Not reported } \\
N_{E}=2\end{array}$ & 26 \\
\hline
\end{tabular}




\begin{tabular}{|c|c|c|c|c|}
\hline $\begin{array}{l}\mathrm{CNF}-[\mathrm{RGO}] \mathrm{n} \text { hybrid paper as } \\
\text { an electrode material and } \\
\text { charge collector. }\end{array}$ & $\begin{array}{l}\mathrm{H}_{2} \mathrm{SO}_{4}-\mathrm{PVA} \text { gel } \\
\text { electrolyte. }\end{array}$ & $\begin{array}{l}\text { Cyclic voltammetry (CV), galvanostatic charge } \\
\text { and discharge, and solid state supercapacitor. }\end{array}$ & $\begin{array}{c}I=4-95 \mathrm{~mA} \mathrm{~cm}^{-2} \\
C_{W E}=\text { Not reported } \\
C_{S}=\text { Not reported } \\
C_{a}=0.78 \mathrm{mF} \mathrm{cm}^{-2} \\
N_{E}=2\end{array}$ & 27 \\
\hline $\begin{array}{l}\mathrm{MnO} 2 / \mathrm{Ni} / \text { graphite/paper } \\
\text { electrodes: multi-layered } \\
\mathrm{MnO} 2 / \mathrm{Ni} / \text { graphite/paper } \\
\text { electrodes that were fabricated } \\
\text { by sequentially coating a } \\
\text { graphite layer, Ni layer, and } \\
\mathrm{MnO} 2 \text { layer on ordinary } \\
\text { cellulose paper. }\end{array}$ & $\begin{array}{l}\mathrm{H}_{2} \mathrm{SO}_{4}-\mathrm{PVA} \text { gel } \\
\text { electrolyte. }\end{array}$ & $\begin{array}{l}\text { Cyclic voltammetry (CV), galvanostatic charge } \\
\text { and discharge, and solid state supercapacitor. }\end{array}$ & $\begin{array}{c}I=0.5 \mathrm{~mA} \mathrm{~g}^{-1} \\
C_{W E}=\text { Not reported } \\
C_{s}=195.7 \mathrm{~F} \mathrm{~g}^{-1} \\
C_{a}=316.4 \mathrm{mF} \mathrm{cm}^{-2} \\
N_{E}=3\end{array}$ & 28 \\
\hline $\begin{array}{l}\text { Sandwich-structured of } \\
\text { graphite/Ni/ } \mathrm{Co}_{2} \mathrm{NiO}_{4}-\mathrm{CP} \text { is } \\
\text { developed as positive } \\
\text { electrode and the graphite/ } \\
\mathrm{Ni} / \mathrm{AC}-\mathrm{CP} \text { as negative } \\
\text { electrode. }\end{array}$ & $1.0 \mathrm{M} \mathrm{KOH}$. & $\begin{array}{l}\text { CVs of each electrode separately and } \\
\text { combined. Also testing of the battery charge } \\
\text { and discharge at different angles of 'flexing' }\end{array}$ & $\begin{array}{c}I=4-15 \mathrm{~mA} \mathrm{~cm}^{-2} \\
C_{W E}=\text { Not reported } \\
C_{s}=\text { Not reported } \\
C_{a}=734 \mathrm{mF} \mathrm{cm}^{-2} \\
N_{E}=3\end{array}$ & 29 \\
\hline $\begin{array}{l}\text { A graphene and cellulose } \\
\text { paper membrane, consisting } \\
\text { of interwoven cellulose fibres } \\
\text { and graphene nanosheets. }\end{array}$ & $1.0 \mathrm{M} \mathrm{H}_{2} \mathrm{SO}_{4}$ & The capacitance was evaluated from the CV. & $\begin{array}{c}I=\text { Not reported } \\
C_{W E}=\text { Not reported } \\
C_{S}=160 \mathrm{~F} \mathrm{~g}^{-1} \\
C_{a}=\text { Not reported } \\
N_{E}=\text { Not reported }\end{array}$ & 30 \\
\hline $\begin{array}{l}\text { Pencil drawing and } \\
\text { electrodeposition utilised to } \\
\text { demonstrate graphite } \\
\text { polyaniline hybrids on paper } \\
\text { and an electrode concept. }\end{array}$ & $1.0 \mathrm{M} \mathrm{H}_{2} \mathrm{SO}_{4}$ & $\begin{array}{l}\text { The electrochemical properties were evaluated } \\
\text { by electrochemical impedance spectroscopy } \\
\text { over the frequency range } 0.01 \mathrm{~Hz} \text { to } 100 \mathrm{kHz} \text {. }\end{array}$ & $\begin{array}{c}I=0.5-4.57 \mathrm{~mA} \mathrm{~cm}^{-2} \\
C_{W E}=101.6 \mu F \\
C_{s}=10.6 \mu F \mathrm{mg}^{-1} \\
C_{a}=3.55 \mu F \mathrm{~cm}^{-2} \\
N_{E}=3\end{array}$ & 31 \\
\hline $\begin{array}{l}\text { Cellulose paper or polyester } \\
\text { textile integrated with carbon } \\
\text { nanotubes. }\end{array}$ & $1.0 \mathrm{M} \mathrm{H}_{2} \mathrm{SO}_{4}$ & The capacitance was evaluated from the CV. & $\begin{array}{c}I=\sim 1{\mathrm{~mA} \mathrm{~cm}^{-2}} \\
C_{W E}=\text { Not reported } \\
C_{S}=256 \mathrm{~F} \mathrm{~g}^{-1} \\
C_{a}=\text { Not reported } \\
N_{E}=3\end{array}$ & 32 \\
\hline
\end{tabular}




\begin{tabular}{|c|c|c|c|c|}
\hline $\begin{array}{l}\text { A polyester cellulose paper } \\
\text { substrate with carbon } \\
\text { nanotube ink. }\end{array}$ & $\begin{array}{l}\mathrm{PVA} / \mathrm{H}_{2} \mathrm{SO}_{4} \text { gel } \\
\text { electrolyte }\end{array}$ & $\begin{array}{l}\text { Capacitance determined by galvanostatic and } \\
\text { cyclic voltammetry methods. }\end{array}$ & $\begin{array}{c}I=0.11 \mathrm{~mA} \mathrm{~cm}^{-2} \\
C_{W E}=\text { Not reported } \\
C_{S}=270 \mathrm{Fg}^{-1} \\
C_{a}=\text { Not reported } \\
\mathrm{E}_{\mathrm{S}}=0.01 \mathrm{~J} \mathrm{mg}^{-1} \\
N_{E}=3\end{array}$ & 33 \\
\hline $\begin{array}{l}\text { Commercially available } \\
\text { pencils drawn on to printing } \\
\text { paper. A range of pencils from } \\
\text { HB to } 9 \mathrm{~B} \text {, numbers of layers } \\
\text { from } 5 \text { to } 20 \text { are investigated. }\end{array}$ & $0.1 \mathrm{M} \mathrm{H}_{2} \mathrm{SO}_{4}$. & $\begin{array}{l}\text { Physical and electrochemical analysis by } \\
\text { SEM/EDX, cyclic voltammetry, and } \\
\text { galvanostatic charge/discharge, to develop a } \\
\text { paper based supercapacitor with pencil drawn } \\
\text { electrodes. }\end{array}$ & 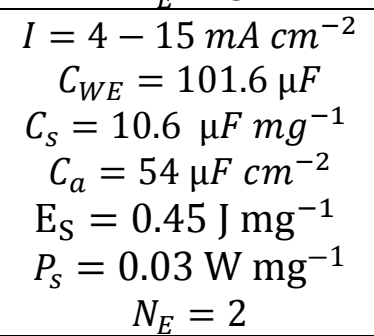 & $\begin{array}{l}\text { This } \\
\text { work }\end{array}$ \\
\hline
\end{tabular}

Table 2 The effective composition of pencils over the complete hardness range utilised in this study.

\begin{tabular}{|c|cccccccccc|}
\hline Hardness & HB & B & 2B & 3B & 4B & 5B & 6B & 7B & 8B & 9B \\
\hline Graphite (\%) & 68 & 71 & 74 & 76 & 79 & 82 & 84 & 87 & 90 & 93 \\
Clay (\%) & 26 & 23 & 20 & 18 & 15 & 12 & 10 & 7 & 5 \\
Wax(\%) & 5 & 5 & 5 & 5 & 5 & 5 & 5 & 5 & 5 & 5 \\
\hline
\end{tabular}


Table 3 The evaluation of the capacitance of the 8B pencil drawn electrode with the parallel capacitive circuit. The specific capacitance of the electrodes considers the weight of the pencil 'lead' deposited on the paper only.

\begin{tabular}{cccccc}
\hline $\begin{array}{c}\text { Circuit Capacitance } \\
(\boldsymbol{\mu F})\end{array}$ & $\mathbf{1 0 0}$ & $\mathbf{2 0 0}$ & $\mathbf{4 2 0}$ & $\mathbf{5 2 0}$ & $\mathbf{6 2 0}$ \\
\hline$\frac{\boldsymbol{d} \boldsymbol{V}}{\boldsymbol{d} \boldsymbol{t}\left(\times \mathbf{1 0}^{-2} \mathbf{V s}^{-1}\right)}$ & 3.58 & 2.09 & 1.02 & 0.87 & 0.71 \\
$\boldsymbol{C}_{\boldsymbol{T o t a l}}(\boldsymbol{\mu} \mathbf{F})$ & 140.0 & 239.3 & 489.4 & 575.1 & 700.0 \\
$\boldsymbol{C}_{\boldsymbol{W E}}(\boldsymbol{\mu F})$ & 19.9 & 19.6 & 34.6 & 27.5 & 40.0 \\
$\boldsymbol{C}_{\boldsymbol{S}}\left(\boldsymbol{\mu} \mathbf{F} \mathbf{~ m g}^{-\mathbf{1}}\right)$ & $( \pm 3.1)$ & $( \pm 2.8)$ & $( \pm 2.9)$ & $( \pm 3.3)$ & $( \pm 2.9)$ \\
& 6.123 & 6.030 & 10.646 & 8.461 & 12.308 \\
$\boldsymbol{E}_{\boldsymbol{S}}\left(\boldsymbol{J} \mathbf{~ m g}^{-\mathbf{1}}\right)$ & 0.619 & 0.361 & 0.176 & 0.150 & 0.122 \\
$\boldsymbol{P}_{\boldsymbol{S}}\left(\boldsymbol{W} \mathbf{m g}^{-\mathbf{1}}\right)$ & 0.0413 & 0.0241 & 0.0117 & 0.0100 & 0.00819 \\
\hline
\end{tabular}




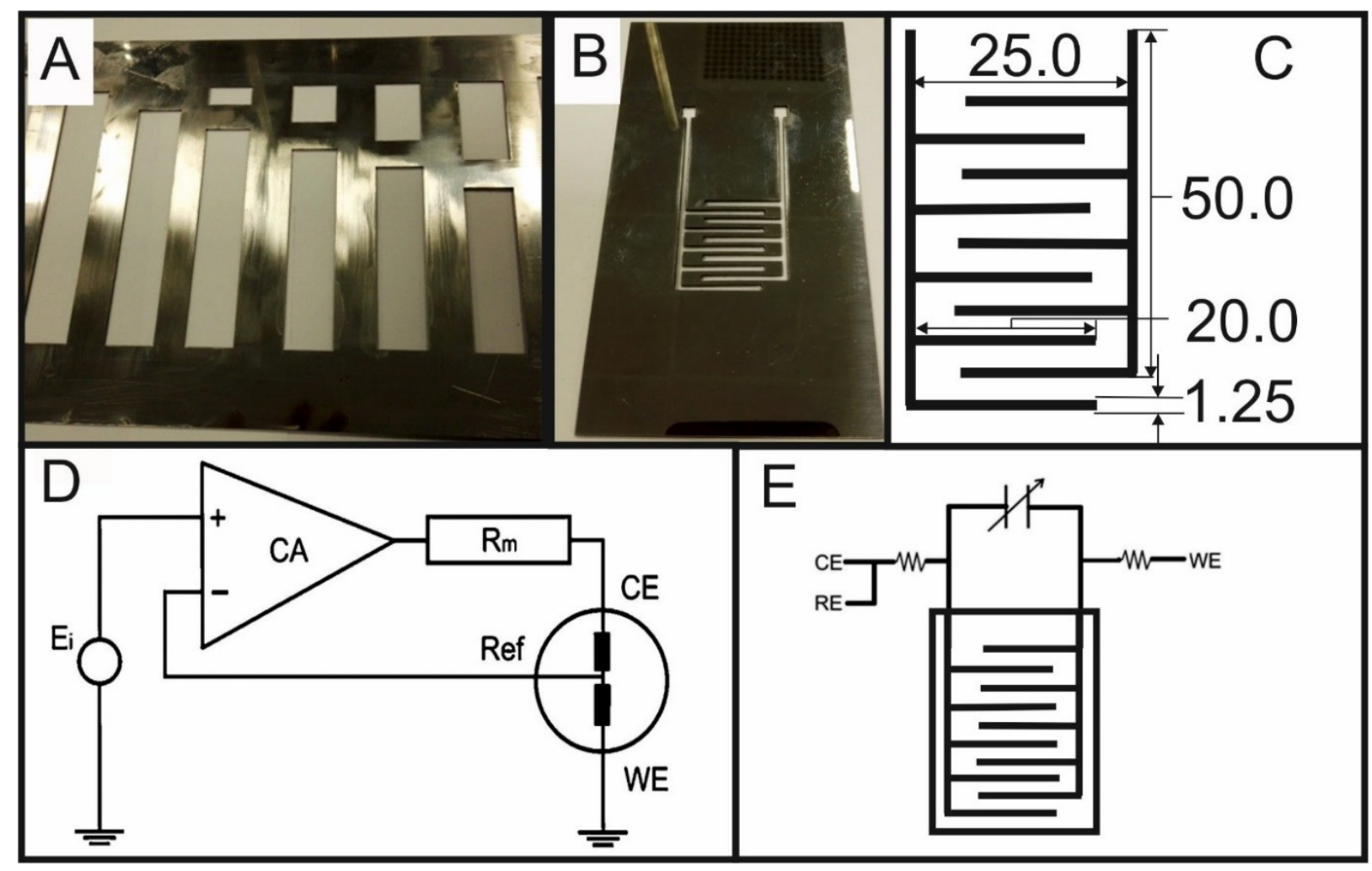

Figure 1 Methodology of manufacturing and characterising the pencil drawn electrodes. A) A stencil designed to generate a series of pencil drawn conductors of fixed width, $2 \mathrm{~cm}$, and varying lengths $1 \mathrm{~cm}$ to $11 \mathrm{~cm}$. B) The stencil for the interdigitated pencil drawn electrode. C) The dimensions of the interdigitated electrode. D) The effective circuit diagram for the analysis circuit when connected to the potentiostat ${ }^{15}$. E) A schematic illustration of the analysis circuit used to investigate the capacitive properties of the electrodes.

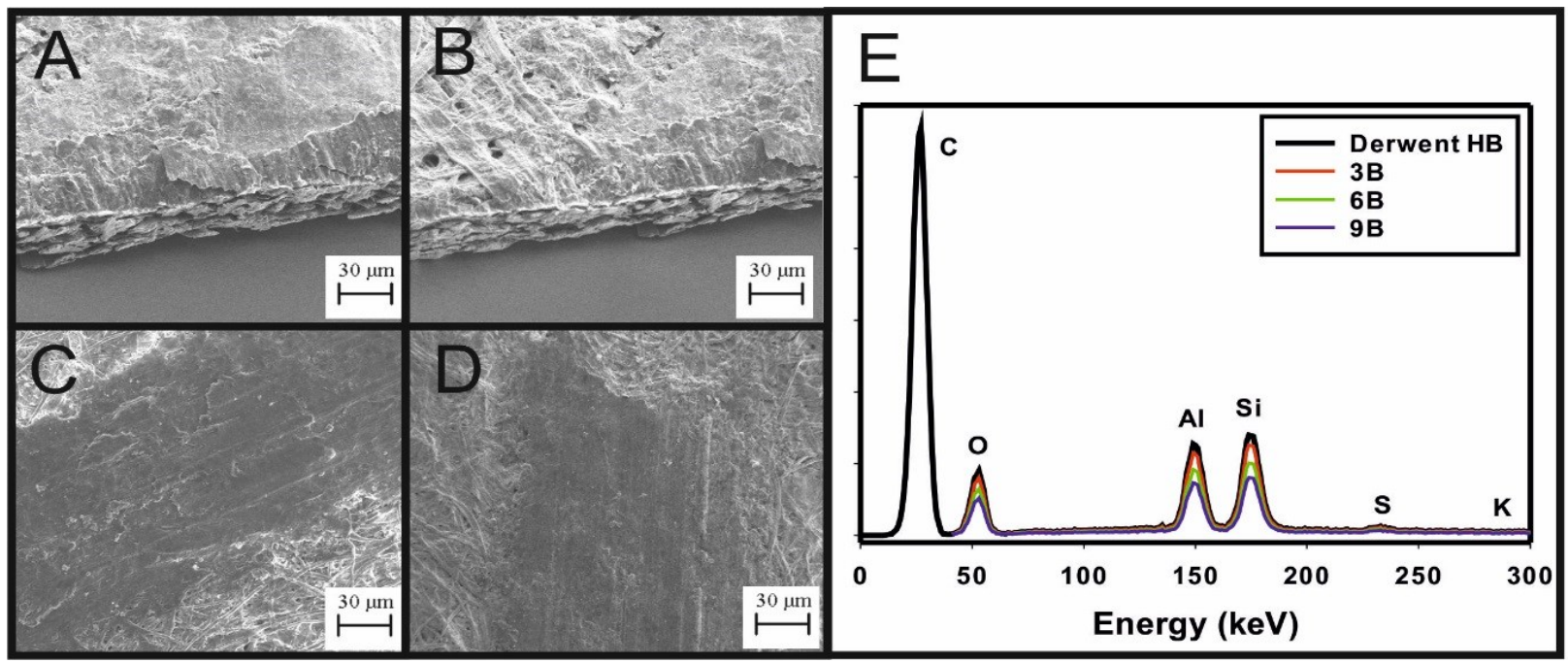

Figure 2 SEM images and EDX characterisation of the pencil traces, $A \& C$ are of an $H B$ pencil drawn electrode, and $B \& D$ are of an $8 \mathrm{~B}$, both with 20 traces. A) The cross section of the pencil drawn electrodes (HB) showing the cellulose fibre structure of the paper remains intact. B) A cross sectional image of the paper and pencil trace (8B). C) An example of the surface structure of the pencil trace on the paper surface (HB), several flakes and edge features. D) A typical pencil trace surface structure (8B). E) EDX of several pencil compositions, normalised by the carbon peaks. This provides and analysis of the effective composition and relative quantity of elements present in the clay and wax present in pencil 'leads'. 


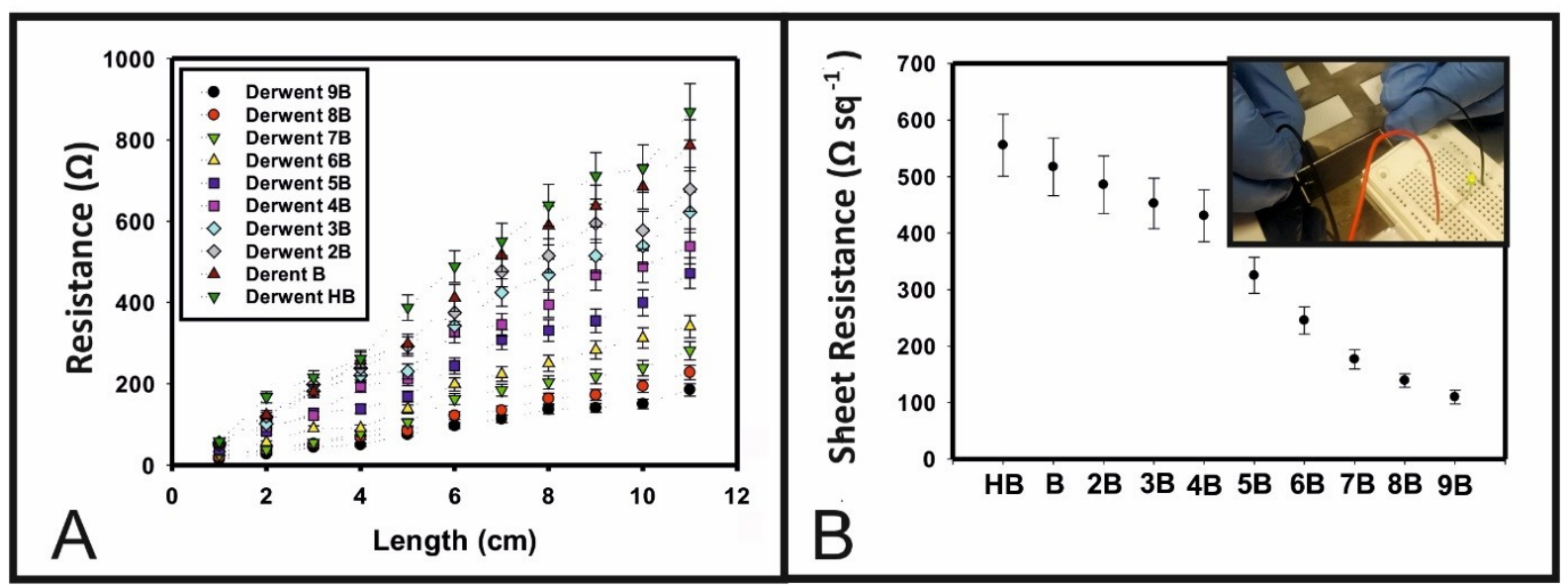

Figure 3 Electrical resistance measurements, A), and sheet resistance values, B), for the pencil compositions HB - 9B.

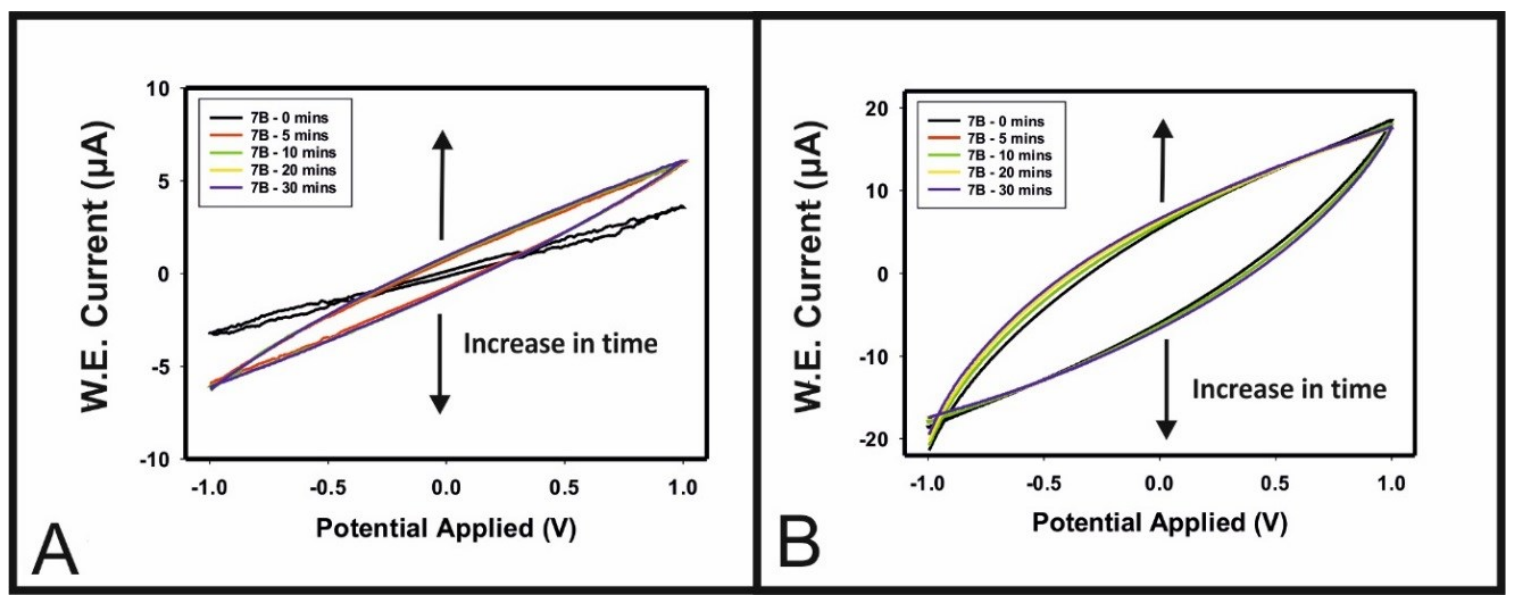

Figure 4 Voltammograms of the 7B pencil drawn electrodes, in $0.1 \mathrm{M} \mathrm{H}_{2} \mathrm{SO}_{4}$ aqueous solution, over the range -1.0 to $1.0 \mathrm{~V}$, both single sided, A), and double sided, B) interdigitated pencil drawn electrodes. 


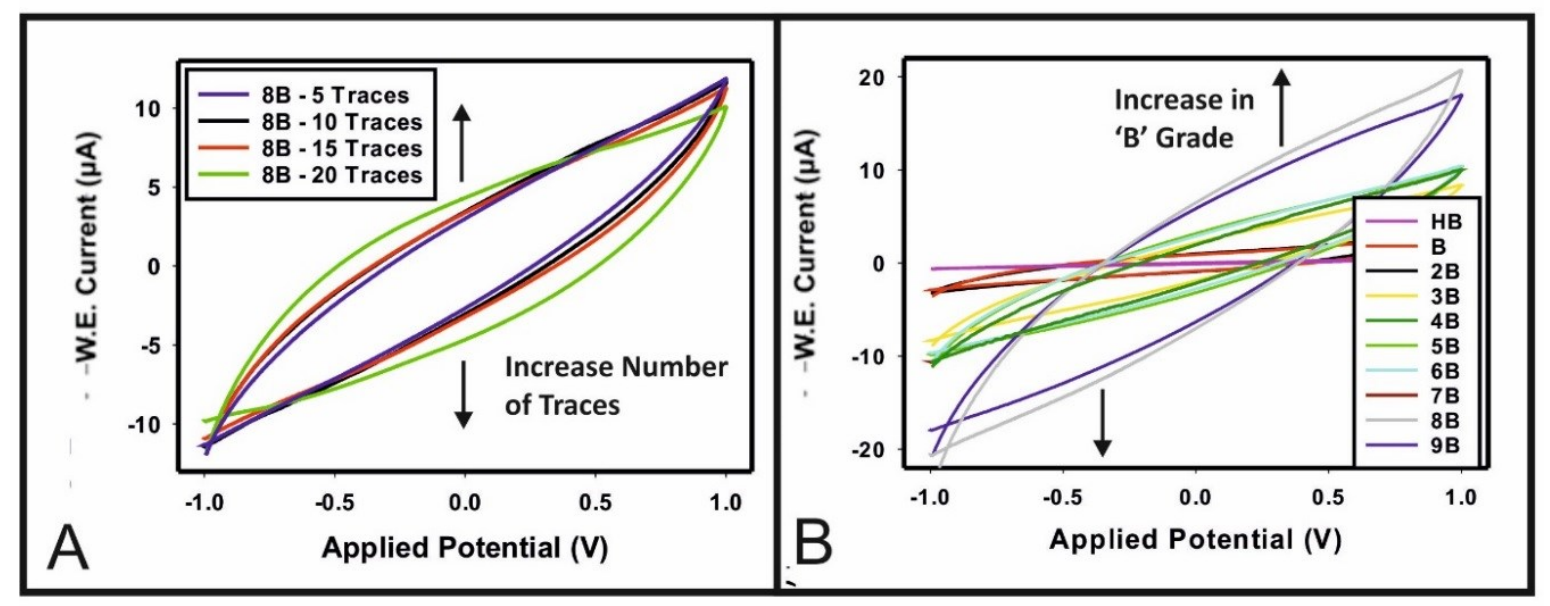

Figure 5 Voltammograms for the $8 \mathrm{~B}$ pencil drawn electrodes, with varying number of traces, $\mathrm{A}$ ), and the full range of commercially available Derwent pencils.

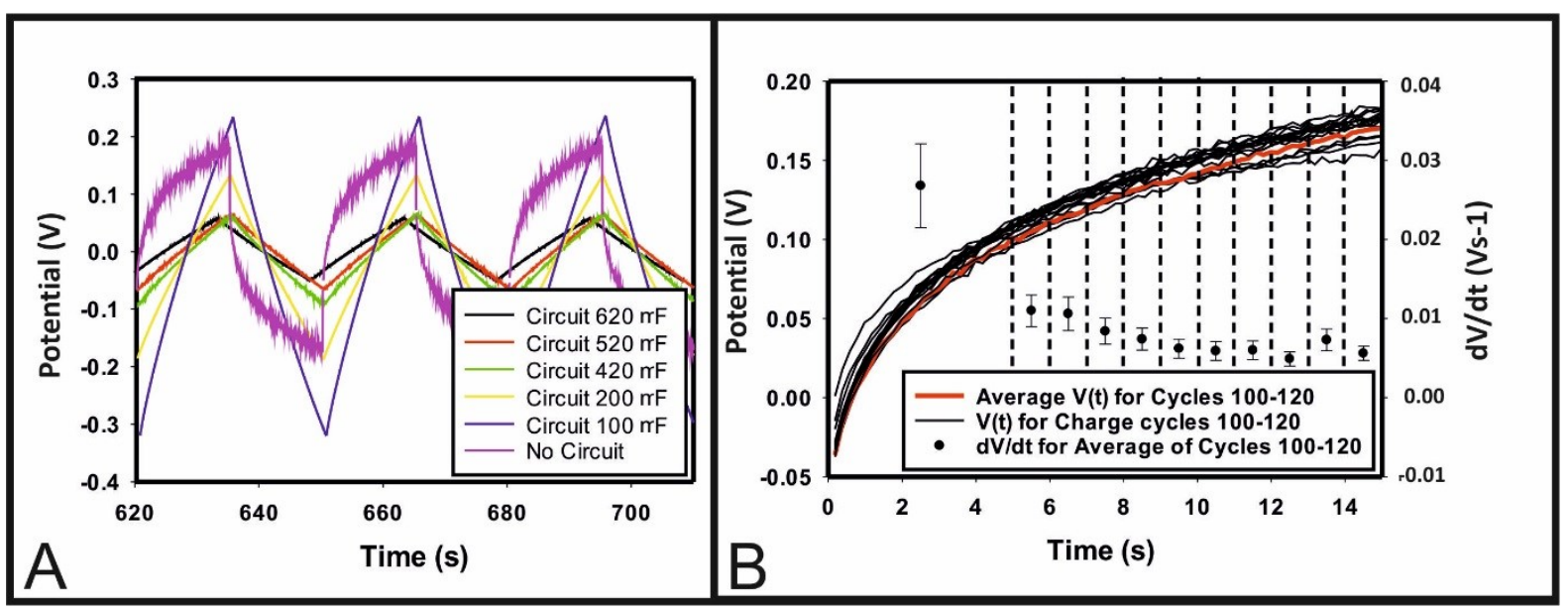

Figure 6 The charge-discharge characteristics of the capacitive system, from the electrode being analysed independently, to the inclusion of the capacitive circuit with capacitance values from 100 to $620 \mu \mathrm{F}$. 


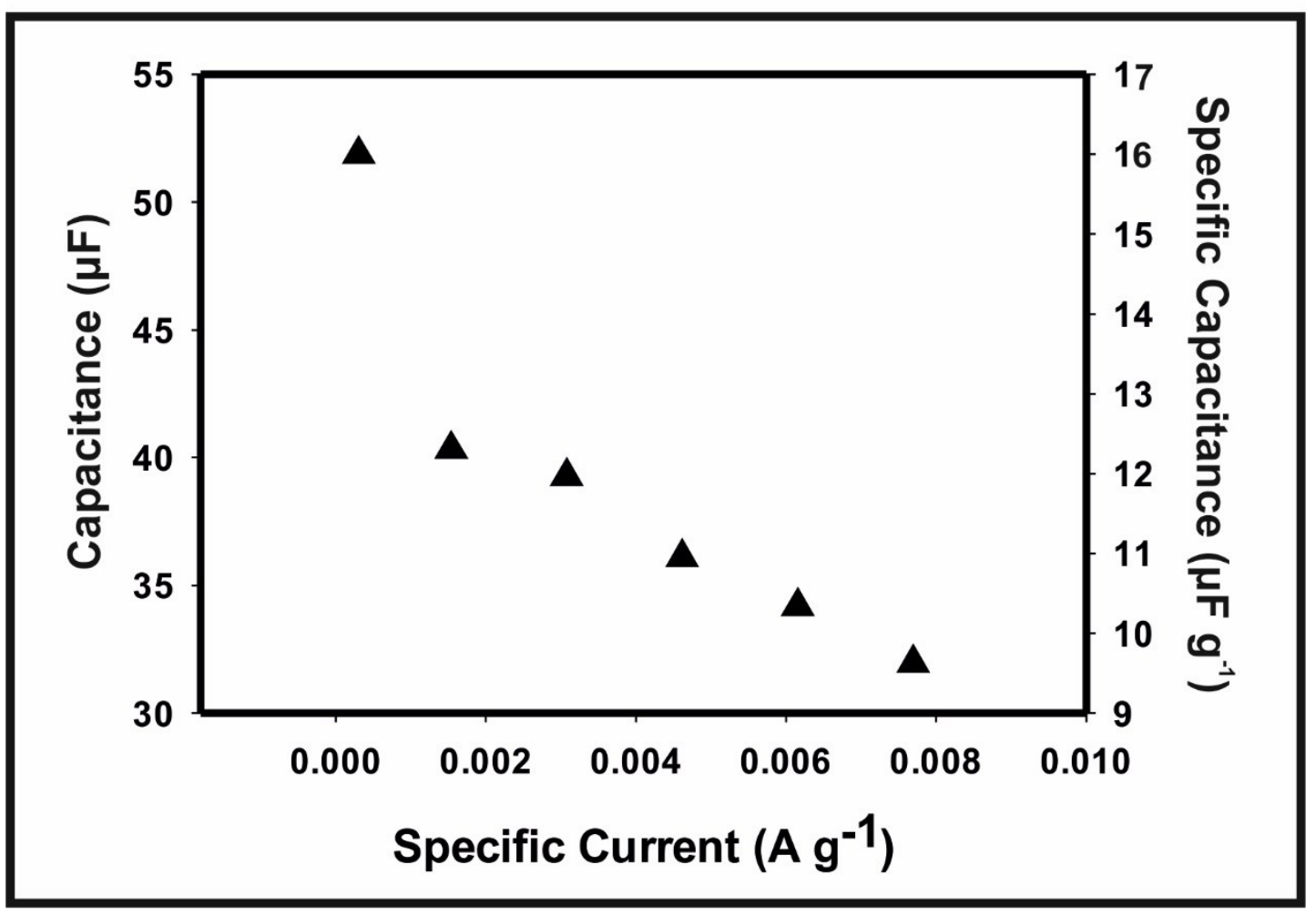

Figure 7 Plot for the effect on the capacitance of the double-sided $8 \mathrm{~B}$ pencil drawn electrode in $0.1 \mathrm{M} \mathrm{H}_{2} \mathrm{SO}_{4}$.

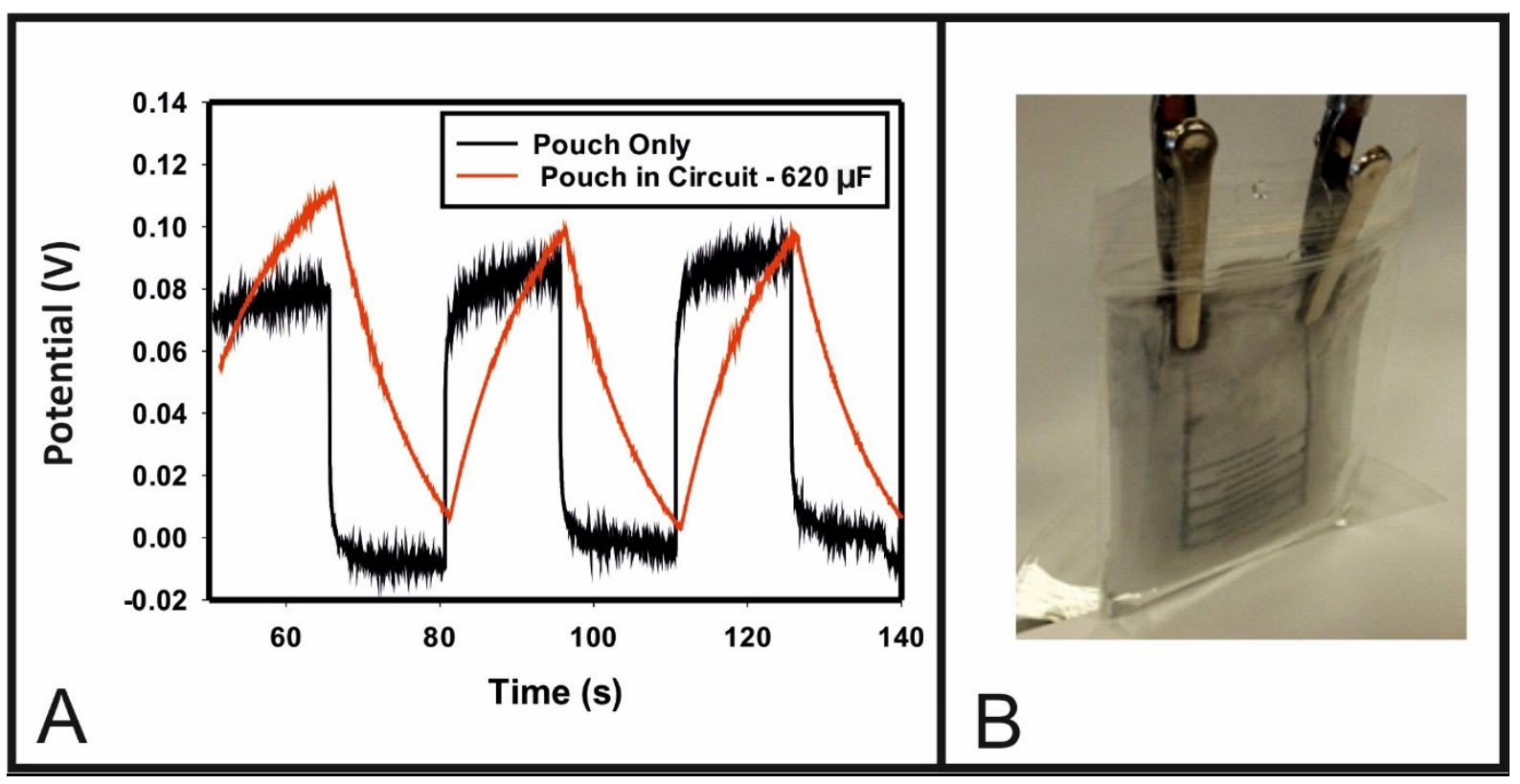

Figure 8 A) The charge-discharge characteristics of the pouch capacitor, both without the parallel circuit, and with a circuit capacitance of $620 \mu \mathrm{F}$. B) A photograph of the pouch arrangement, the pouch consists of 5 double sided 8B pencil drawn electrodes in parallel, with paper spacers between each, the pouch is filled with $3 \mathrm{ml}$ of $0.1 \mathrm{M}_{\text {of }} \mathrm{H}_{2} \mathrm{SO}_{4}$. 


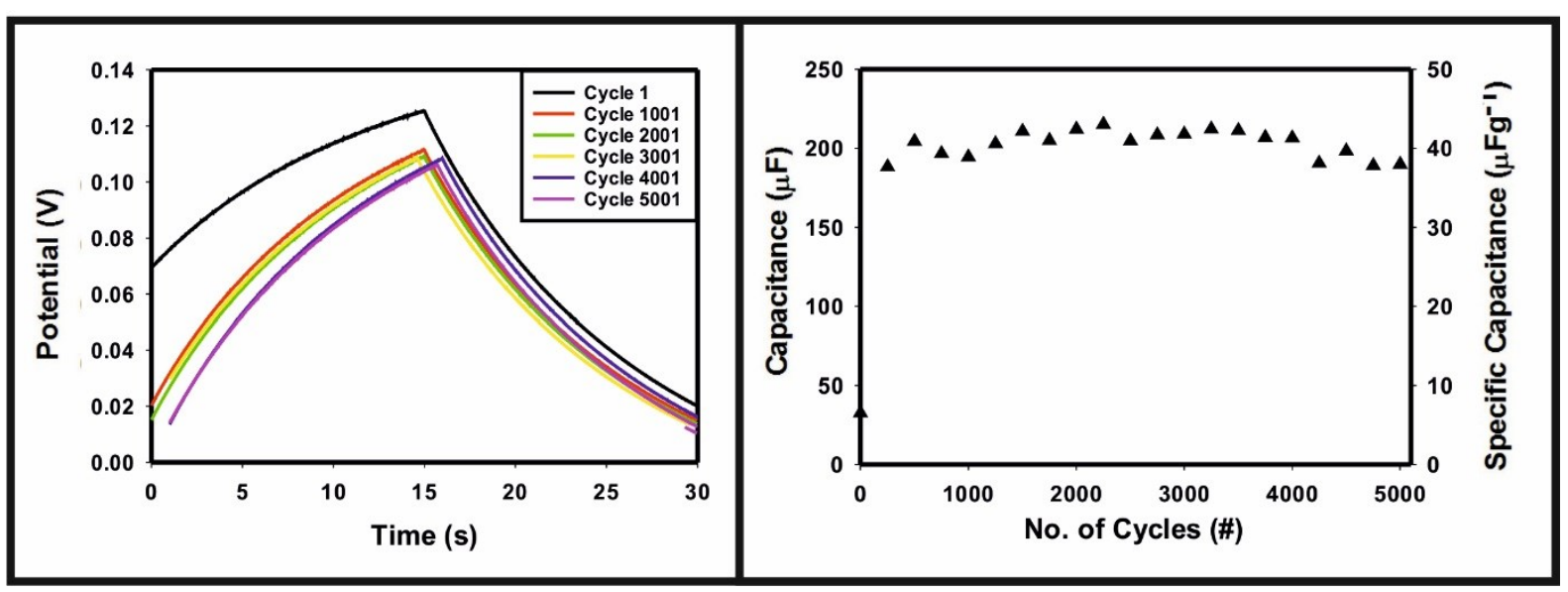

Figure 9 The performance of the P-SC over a long lifetime test. A) The charge/discharge characteristics of cycles 1 to 5001 , for every 1000th cycle. B) The effective capacitance of the P-SC over the entire test period.

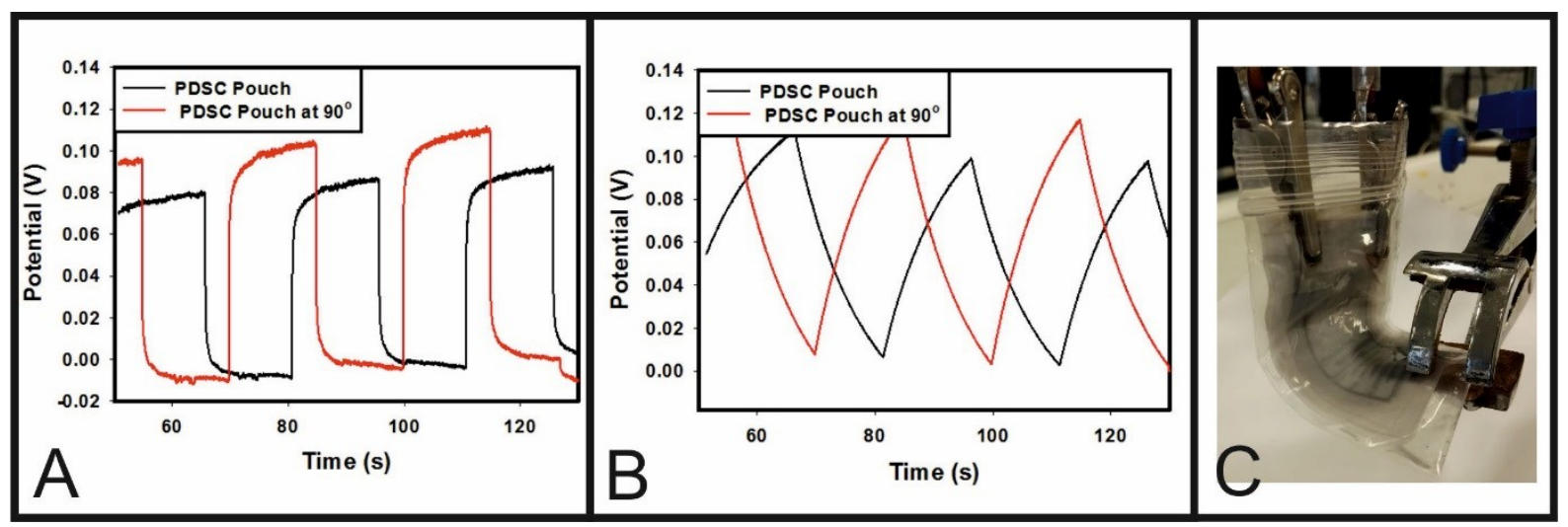

Figure 10 Charge/discharge characteristics of the P-SC; A) Without the circuit, B) with the circuit of capacitance $620 \mu \mathrm{F}, \mathrm{C}$ ) a photograph of the bent P-SC held in position by a clamp. 


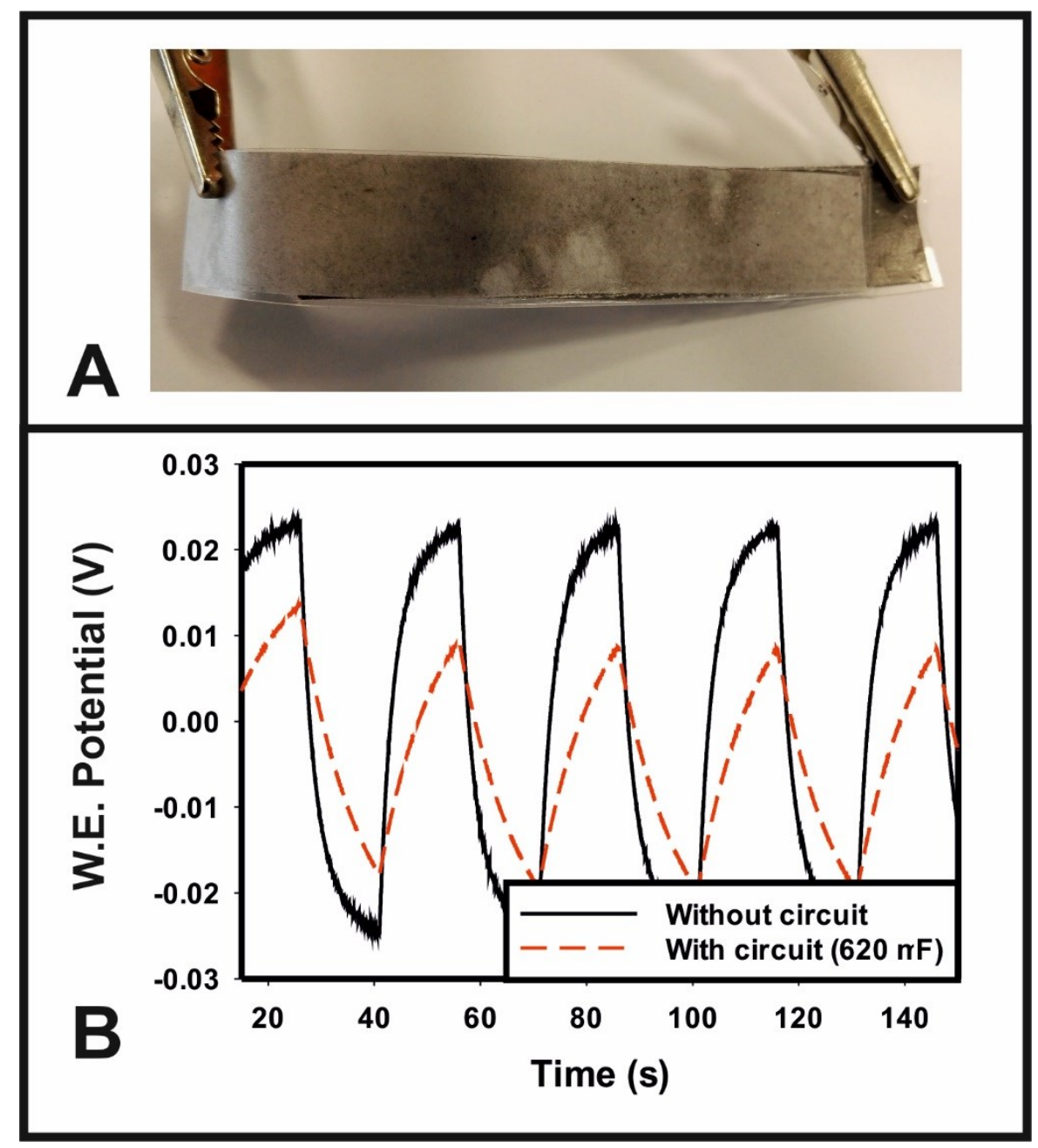

Figure 11 A photograph of a solid state P-SC, using an H2SO4-PVA electrolyte, A), and the characteristic charge performance of the device with a $5 \mu \mathrm{A}$ charging current, B). 


\section{References:}

1. K. C. Honeychurch and J. P. Hart, Advances in Analytical Chemistry, 2012, 2, 46-52.

2. K. Kalcher, I. Švancara, R. Metelka, K. Vytřas, A. Walcarius, Journal, 2006, Vol. 4, 284-429.

3. N. Kurra and G. U. Kulkarni, Lab on a Chip, 2013, 13, 2866-2873.

4. A. M. Bond, P. J. Mahon, J. Schiewe and V. Vincente-Beckette, Analytica chemica acta, 1997, 67-74.

5. N. Chauhan, J. Narang and C. Pundir, American Journal of Analytical Chemistry, 2010, 41-46.

6. D. King, J. Friend and J. Kariuki, Journal of Chemistry Education, 2010, 507-509.

7. D. Demetriades, A. Economou and A. Voulgaropoulos, Analytica Chimica Acta, 2004, 167-172.

8. Y. W. Hartati, S. Topkaya, I. P. Maksum and M. Ozsoz, Advances in Analytical Chemistry 2013, 20-27.

9. K. Pokpas, S. Zbeda, N. Jahed, N. Mohamed, P. G. Baker and E. I. Iwuoha, International Journal of Electrochemical Science, 2014, 736-759.

10. M. Vestergaard, K. Kerman and E. Tamiya, Analytica Chimica Acta, 2005, 273-281.

11. J. A. Denman, I. M. Kempson, W. M. Skinner and K. P. Kirkbride, Forensic Science International, 2007, 175, 123-129.

12. S. Cantu, A. A. Cantu, R. Brunelle and A. Lyter, Journal of Forensic Sciences, 1978, 23, 643-661.

13. Y. Wang and H. Zhou, Energy and Evironmental Science, 2011, 4, 1704-1707.

14. G. Zheng, L. Hu, H. Wu, X. Xie and Y. Cui, Energy and Environmental Science, 2011, 4, 33683373.

15. D. K. Kampouris, X. Ji, E. P. Randviir and C. Banks, RSC Advances, 2015, 5, 12782-12791.

16. L. J. V. d. Pauw, Phillips research Reports, 1958, 12, 1-9.

17. A. P. R. d. Souza, C. W. Foster, A. V. Kolliopoulos, M. Bertotti and C. E. Banks, Analyst, 2015, 140, 4130-4136.

18. H. P. Cong, X. C. Ren, P. Wang and S. H. Yu, Energy and Environmental Science, 2013, 6, 11851191.

19. K. Gao, Z. Shao, J. Li, X. Wang, X. Peng, W. Wang and F. Wang, Journal of Material Chemestry, 2013, 1.

20. M. Khalid, M. A. Tumelero and A. A. Pasa, RSC Advances, 2015, 5, 62033-62044.

21. S. Boukhalfa, K. Evanoff and G. Yushin, Energy and Environmental Science, 2012, 5, 6872-6879.

22. H. Nan, L. Yu, W. Ma and X. Z. B. Geng, Dalton Transactions, 2015, 44.

23. K. Xu, R. Zou, W. Li, Q. Liu, X. Liu, L. Ana and J. Hu, Journal of Material Chemistry A, 2014, 2.

24. W. Jiang, K. Zhang, L. Wei, D. Yu, J. Wei and Y. Chen, Nanoscale, 2013, 5.

25. H. Li, B. Wang, X. He, J. Xiao, H. Zhang, Q. Liu, J. Liu, J. Wang, L. Liuc and P. Wang, Journal of Material Chemistry A, 2015, 3.

26. S. Wang and R. A. W. Dryfe, Journal of Material Chemistry A., 2013, 1.

27. K. Gao, Z. Shao, X. Wu, X. Wang, Y. Zhang, W. Wang and F. Wang, Nanoscale, 2013, 5.

28. J. X. Feng, Q. Li, X. F. Lu, Y. X. Tonga and G. R. Li, Journal of Material Chemistry A. , 2014, 2, 2985-2992.

29. J. X. Feng, S. H. Ye, A. L. Wang, X. F. Lu, Y. X. Tong and G. R. Li, Advanced Functional Material 2014, 7093-7101.

30. Z. Weng, Y. Su, D.-W. Wang, F. Li, J. Du and H.-M. Cheng, Advanced Energy Materials, 2011, 1, 917-922.

31. B. Yao, L. Yuan, X. Xiao, J. Zhang, Y. Qi, J. Zhou, J. Zhou, B. Hu and W. Chen, Nano Energy, 2013, 2, 1071-1078.

32. Z. Gui, H. Zhu, E. Gillette, X. Han, G. W. Rubloff, L. Hu and S. B. Lee, ACS Nano, 2013, 7, 60376046.

33. P. Karthika, N. Rajalakshmi and K. S. Dhathathreyan, ChemPhysChem, 2013, 14, 3822-3826. 


\title{
Electronic Supplementary Information (ESI) \\ Pencil Drawn Paper Based Supercapacitors
}

\author{
Michael P. Down ${ }^{1}$, Christopher W. Foster ${ }^{1}$, Xiaobo $\mathrm{Ji}^{2}$ and Craig E. Banks ${ }^{1}$ \\ ${ }^{I}:$ Faculty of Science and Engineering, School of Science and the Environment, Division of Chemistry \\ and Environmental Science, Manchester Metropolitan University, Chester Street, Manchester, MI \\ $5 G D, U K$. \\ ${ }^{2}$ :Key Laboratory of Resources Chemistry of Nonferrous Metals, Ministry of Education, College of \\ Chemistry and Chemical Engineering, Central South University, Changsha, 410083 (PR China)
}




\section{Electronic Supplementary Information}

A systematic approach to characterising the capacitance of an electrode pair in parallel circuit with a capacitor is presented here. In order to best describe the benefit of this approach, the principles of capacitor theory should be understood. A specific example can be used, with three capacitors, which illustrates how utilising a parallel circuit can improve the interpretation of results. In this example we consider three capacitors of capacitance $C_{1}, C_{2}$ and $C_{3}$. We will assume that the capacitor $C_{1}$ is the supercapacitor such that $C_{1}=C_{\text {supercapacitor }}$. The first case where the capacitors are connected in parallel, as shown in ESI Figure 1. In this case the potential across the capacitors is the same:

$$
V=V_{2}=V_{3}=V_{\text {Supercapacitor }}
$$

and as such the total charge is distributed equally across the capacitors:

$$
Q=Q_{2}=Q_{3}=Q_{\text {Supercapacitor }}
$$

and consequently:

$$
C_{\text {total }} V=C_{2} V_{2}+C_{3} V_{3}+C_{\text {Supercapacitor }} V_{\text {Supercapacitor }}
$$

but from ESI equation 1) we have:

$$
C_{\text {total }} V=C_{2} V+C_{3} V+C_{\text {Supercapacitor }} V
$$

and finally

$$
C_{\text {total }}=C_{2}+C_{3}+C_{\text {Supercapacitor }}
$$

In this example, the total capacitance of the parallel circuit is the sum of all the capacitances of each of the parallel branches.

The second case is where there are three capacitors in series as shown in ESI Figure 1B. In this case the potential is split between each of the components in series:

$$
V=V_{2}+V_{3}+V_{\text {Supercapacitor }}
$$

and

$$
V=V_{2}+V_{3}+V_{\text {Supercapacitor }}
$$

therefore

$$
\frac{Q}{C_{\text {total }}}=\frac{Q}{C_{2}}+\frac{Q}{C_{3}}+\frac{Q}{C_{\text {supercapacitor }}}
$$

and finally

$$
\frac{1}{C_{\text {total }}}=\frac{1}{C_{2}}+\frac{1}{C_{3}}+\frac{1}{C_{\text {supercapacitor }}}
$$

In this case the total capacitance of the series circuit is the sum of the inverse capacitances of the components.

If we consider the effect of this comparison on the analysis of the capacitive properties of the supercapacitor we can see the benefit of analysing the properties in a circuit of know capacitance. ESI Figure 2 shows the various arrangements for analysis of the supercapacitor in parallel with a $100 \mu \mathrm{F}$ capacitor. Either a single $100 \mu \mathrm{F}$ capacitor is utilised in parallel show in ESI Figure 1B or a variable capacitor system is set to $100 \mu \mathrm{F}$ in parallel, shown on ESI Figure 1A. The effect this has on the observed charging cycle and the interpretation of the $d V / d t$ are shown in ESI Figure 1C. As a 
commercial grade capacitor has a nominally linear response, the resulting curve is a combination of a linear curve and the plateauing 'shark-fin' shaped curve that is often seen in experimental supercapacitor characterisation. The resulting curve still presents a relatively curved shape and as such poses the same problem as before, in that the determination of where to take the gradient for the characteristic capacitance is undefined. In order to address this, further evaluations of varying parallel capacitances are investigated.

By increasing the parallel capacitance, the effect on the nominal gradient of the charging cycles can be seen. ESI Figure 3 shows the arrangements for measuring in parallel with a $200 \mu \mathrm{F}$ capacitor, or two $100 \mu \mathrm{F}$ capacitors, which as shown previously are the same. In this case, the line is significantly smoother still and straighter. Increasing the parallel capacitance further still, to $620 \mu \mathrm{F}$, shown in ESI Figure 4, the charge cycles are near linear in behaviour. As a result, the gradient of the whole line can be utilised to determine the capacitive properties of the system, and equation 5 from the main body of text can be used to interpret the capacitance for the working electrode.

The result of this analysis is a systematic approach for providing a true value of the capacitance of an electrode without the risk of misinterpretation of the data. Also by utilising the component in a system the approach to the analysis of electrode properties, the set-up is limited to a 2-wire analysis, which is commercially more useful in terms of supercapacitors. This is a benefit, also, as there is yet to be a standardized approach to such analysis, as shown in Table 1. This develops a uniform approach for all researchers, providing a system that improves repeatability and cohesion amongst the field. The approach consists of the following steps;

1) Perform charge/discharge cycles with the system alone, without any parallel capacitance;

2) Interpret the capacitance without the circuit;

3) Insert the variable capacitor/capacitor circuit in parallel with a low capacitance, of the order of the value extracted from the interpretation without the circuit in steps 1) and 2);

4) Re-interpret the capacitance from the resulting charge cycle, with the parallel circuit in place.

5) If the charge properties are still not linear increase the capacitance until a linear signal is achieved;

6) Interpret the true capacitance from the resulting linear charge response.

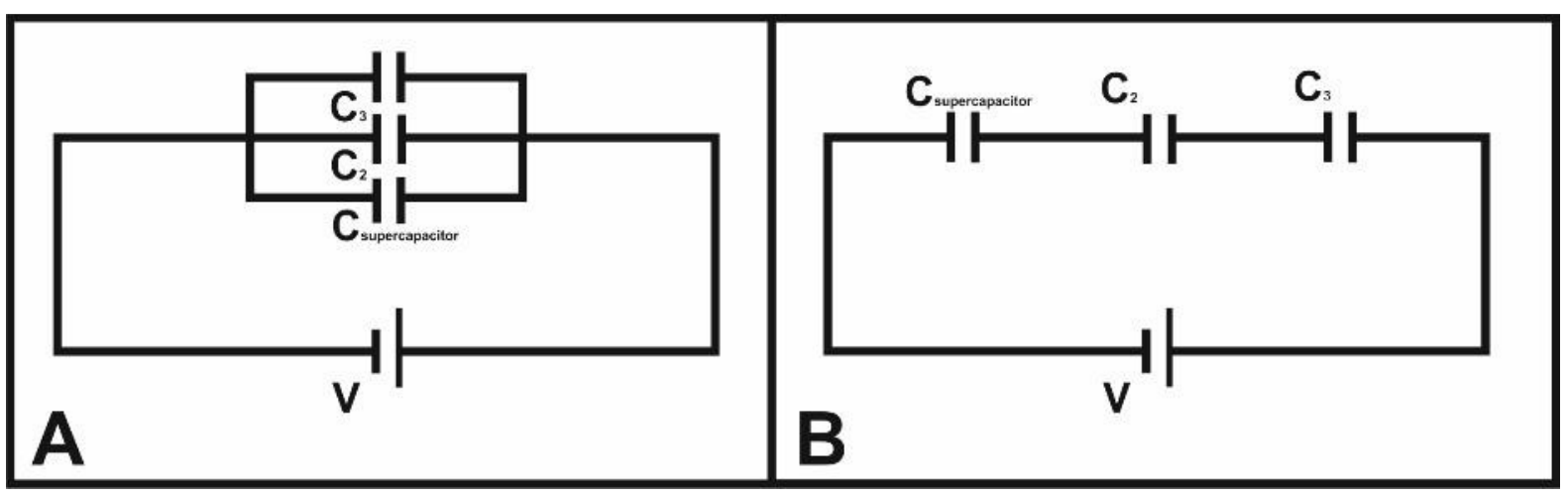

ESI Figure 1 Capacitance circuits for the three-capacitor system, A) in parallel and B) in series. 


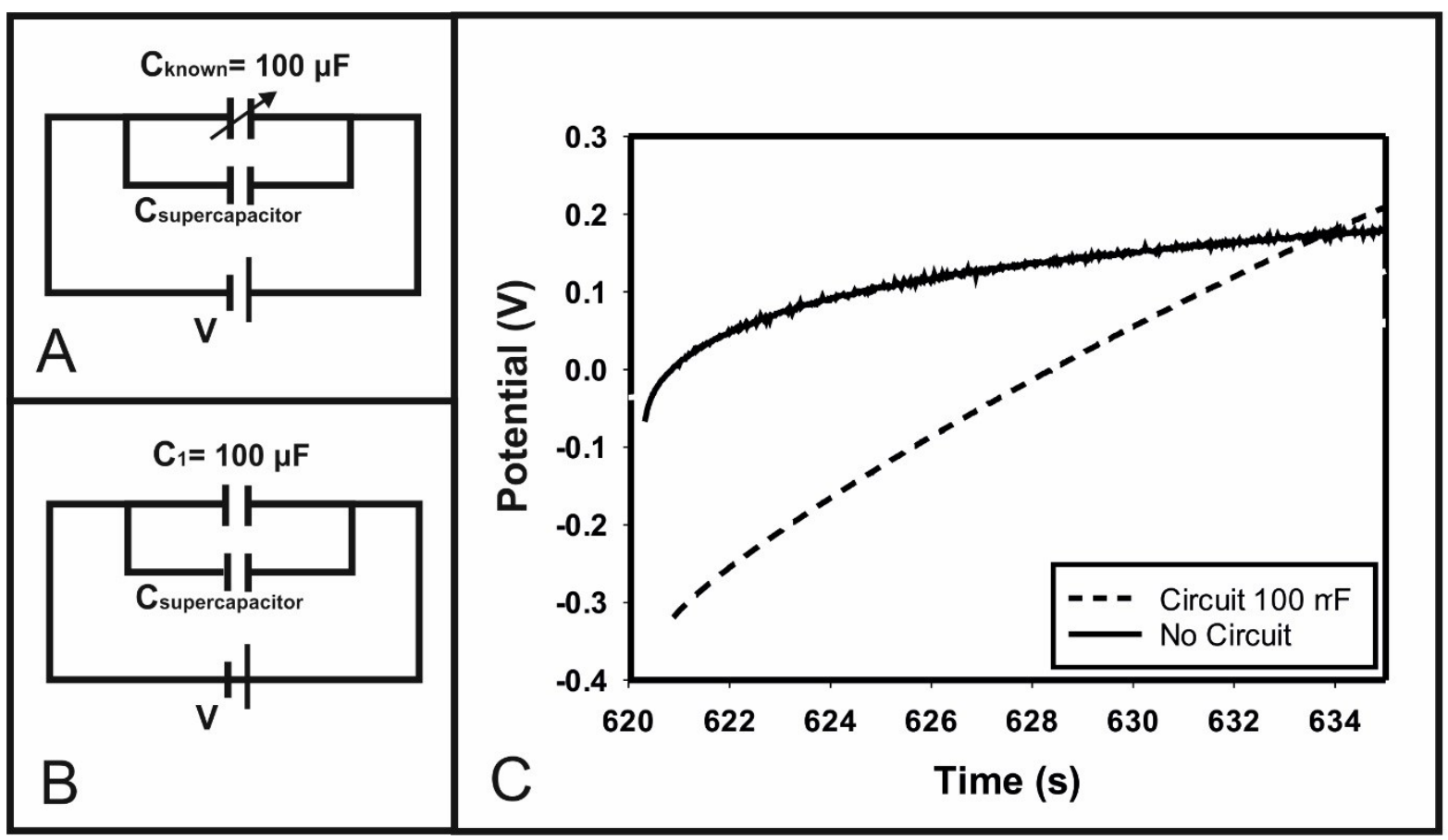

ESI Figure 2 Evaluation of the capacitance of the supercapacitor integrated into a parallel circuit for $100 \mu \mathrm{F}$.

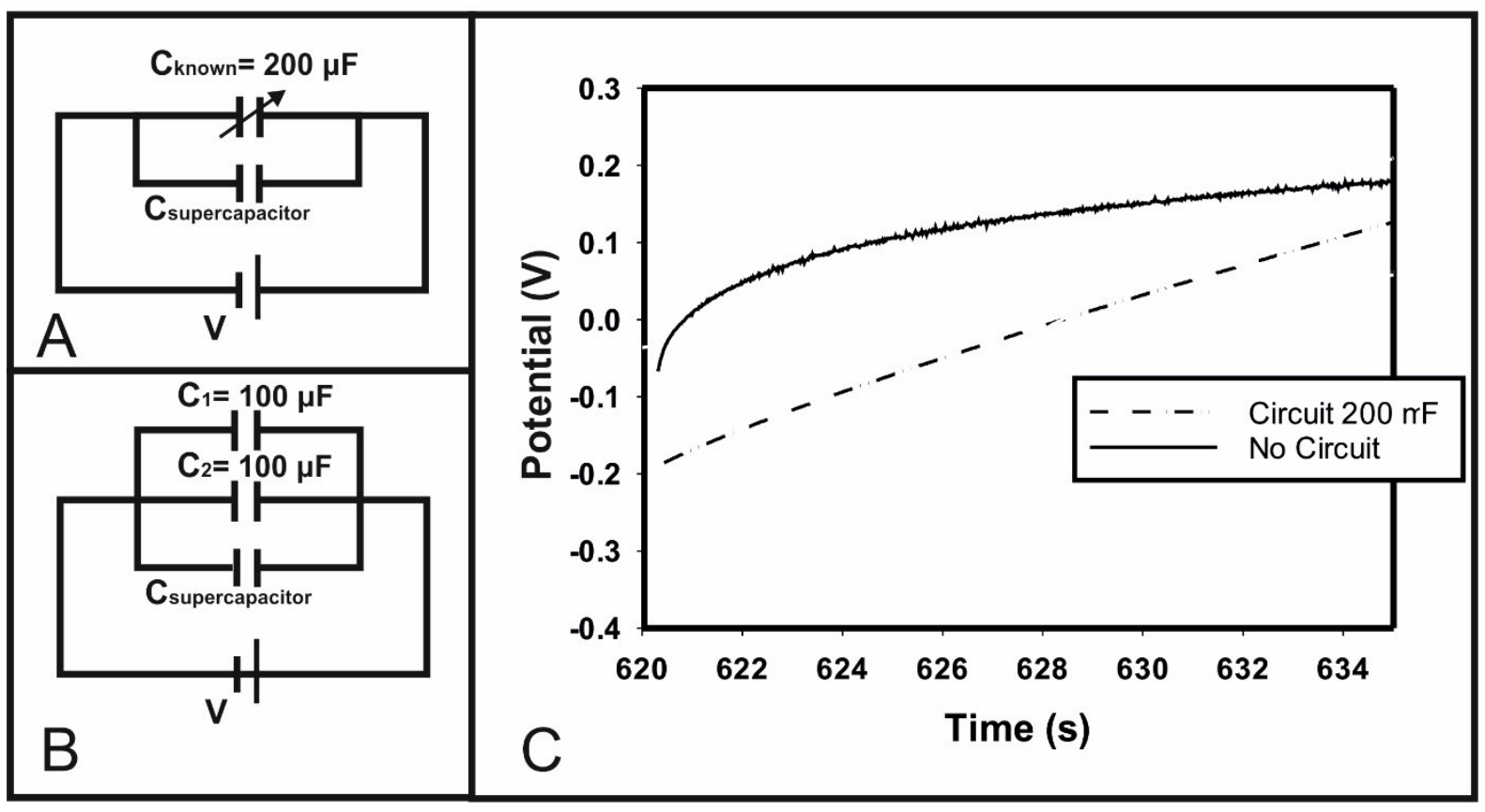

ESI Figure 3 Evaluation of the capacitance of the supercapacitor integrated into a parallel circuit for $200 \mu \mathrm{F}$. 


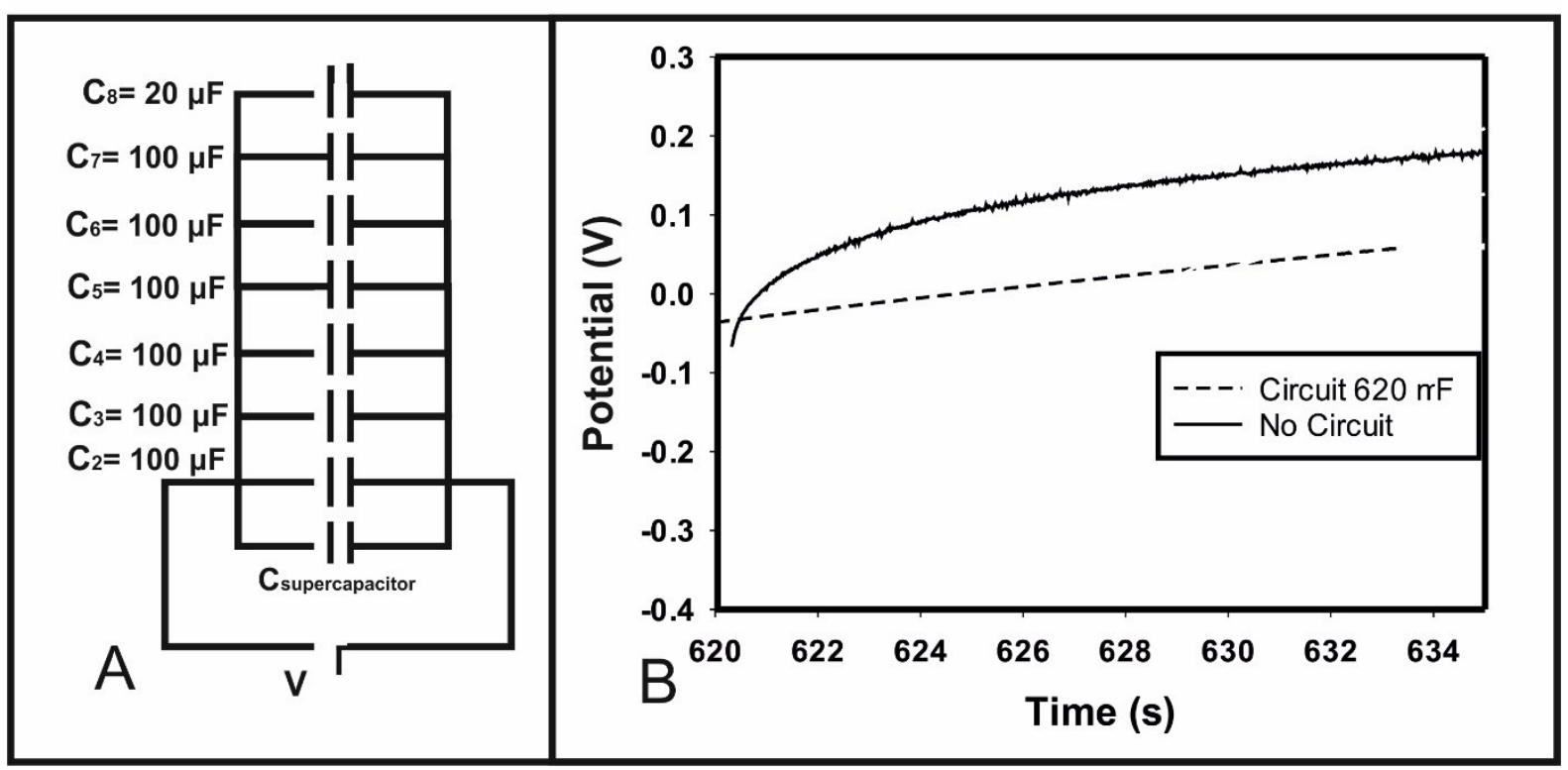

ESI Figure 4 Evaluation of the capacitance of the supercapacitor integrated into a parallel circuit for $620 \mu \mathrm{F}$. 